\title{
Solitons Northeast of Tung-Sha Island During the ASIAEX Pilot Studies
}

\author{
Ying-Jang Yang, Tswen Yung Tang, M. H. Chang, Antony K. Liu, Ming-Kuang Hsu, and Steven R. Ramp
}

\begin{abstract}
In a recent study, satellite images have shown that internal solitons are active in the northern South China Sea (SCS). During the Asian Seas International Acoustic Experiment (ASIAEX) pilot studies, current profiler and thermistor chain moorings were deployed in the spring of 1999 and 2000 to investigate internal solitons northeast of Tung-Sha Island on the continental slope of the northern SCS. Most of the observed internal solitons were first baroclinic mode depression waves. The largest horizontal current velocity, vertical displacement, and temperature variation induced by the internal solitons were around $240 \mathrm{~cm} / \mathrm{s}, 106 \mathrm{~m}$, and $11{ }^{\circ} \mathrm{C}$, respectively, while the estimated nonlinear phase speed was primarily westward at $152 \pm 4 \mathrm{~cm} / \mathrm{s}$. The observed internal solitons could be categorized as four types. The first type is the incoming wave from deep water and can be described reasonably well with the $\mathrm{KdV}$ equation. The second and third types are in the transition zone before and close to the turning point (where the upper and lower layer depths are equal), respectively. These two types of solitons were generally near the wave-breaking stage. The fourth type of soliton is a second baroclinic mode and probably was locally generated. The time evolutions are asymmetric, especially at the middle depths. A temperature kink following the main pulse of the soliton is often seen. Higher order nonlinear and shallow topographic effects could be the primary cause for these features.The appearance/disappearance of internal solitons coincides mostly with spring/neap tide. The internal soliton is irregularly seen during the neap tide period and its amplitude is generally small. The time interval between two leading solitons is generally around $12 \mathrm{~h}$. The first baroclinic mode of the semidiurnal tide has a larger amplitude than the diurnal tide and could redistribute its energy into the soliton.
\end{abstract}

Index Terms-Internal wave, nonlinear wave, soliton, South China Sea (SCS).

Manuscript received October 9, 2003; revised April 26, 2004. This work was supported by the National Science Council, Taiwan, R.O.C., under Grant NSC 90-2611-M-012-001-OP2 and Grant NSC 90-2611-E-012-001 awarded to Y.-J. Yang, Grant NSC 89-2611-M-002-027 awarded to T. Y. Tang, and Grant NSC 89-2611-M-019-014-OP2 awarded to M.-K. Hsu, and by the United States Office of Naval Research under Grant N00014-00-F-0165 awarded to A. K. Liu and Grant N00014-01-WR-20044 awarded to S. R. Ramp.

Y.-J. Yang is with the Department of Marine Science, Chinese Naval Academy, Kaohsiung 813, Taiwan, R.O.C.

T. Y. Tang and M. H. Chang are with the Institute of Oceanography, National Taiwan University, Taipei 106, Taiwan, R.O.C.

A. K. Liu is with the Goddard Space Flight Center, National Aeronautics and Space Administration, Greenbelt, MD 20771, USA.

M.-K. Hsu is with the Kuang Wu Institute of Technology, Taipei 112, Taiwan, R.O.C.

S. R. Ramp is with the Department of Oceanography, Naval Postgraduate School, Monterey, CA 93943 USA.

Digital Object Identifier 10.1109/JOE.2004.841424

\section{INTRODUCTION}

A N INTERNAL solitary wave is a localized internal gravity wave that occurs in a stratified fluid. It induces strong vertical motion, vertical shear of horizontal velocity, density perturbations, and probably nutrient pumping [1]. It also impacts the stability of oil platforms [2], the security of submarine navigation [3], and underwater acoustic propagation [4]-[7]. In 1834, Russell [8], [9] made the first observation of solitary waves. Boussinseq [10] and Korteweg and deVries [11] gave a theoretical description, hereafter referred to as $\mathrm{KdV}$, which represented the extent of physical understanding of solitary waves up to that time. The solitary wave has a particle-like behavior. Zabusky and Kruskal [12] coined the word "soliton" to describe it.

Apel et al. [3] proposed two possible mechanisms for the generation of an internal soliton: 1) coupling of energy between tidal modes and 2) the release of a standing lee wave off the shelf break. In the former generation mechanism, energy from the barotropic tide is scattered into the internal modes within the tidal band at the shelf break. Here, the mode angle of the internal propagation characteristics coincides with the angle of the sloping bottom. The internal tides then scatter energy nonlinearly into the buoyancy band as they propagate shoreward. In the second mechanism, a strong barotropic tidal flow over a sill establishes a standing lee wave. At the onset of the flow reversal, typically occurring at slack tide, the lee wave travels upshelf as internal tides couple energy into the buoyancy band as soliton wave packets.

Assuming a two-layer ocean, Liu et al. [13] have discussed the propagation and transformation of the internal soliton from the deep ocean to shallow water. The internal soliton is a depression wave in the deep ocean. When it passes the turning point, where the thickness of upper and lower ocean water column are equal, the depression wave transforms into an elevation wave. The area of transformation is called a transition zone [14], [15]. During the transformation from a depression to an elevation wave, the soliton changes its shape gradually. In the transition zone, the coefficient of quadratic nonlinearity goes to zero in the typical KdV theory and the cubic or higher order nonlinear effect becomes important [14], [16]-[18]. When the internal soliton propagates from the deep ocean to the continental-slope region, the shoaling effect does not allow the soliton tail to return to its initial state and the mass is not conserved [14], [15], [19]. The higher order nonlinear effect of shoaling may generate the "kink" of the interface displacement followed by the main pulse of the soliton in the transition zone [15], [20] and reduce the soliton phase speed [14], [21]. 


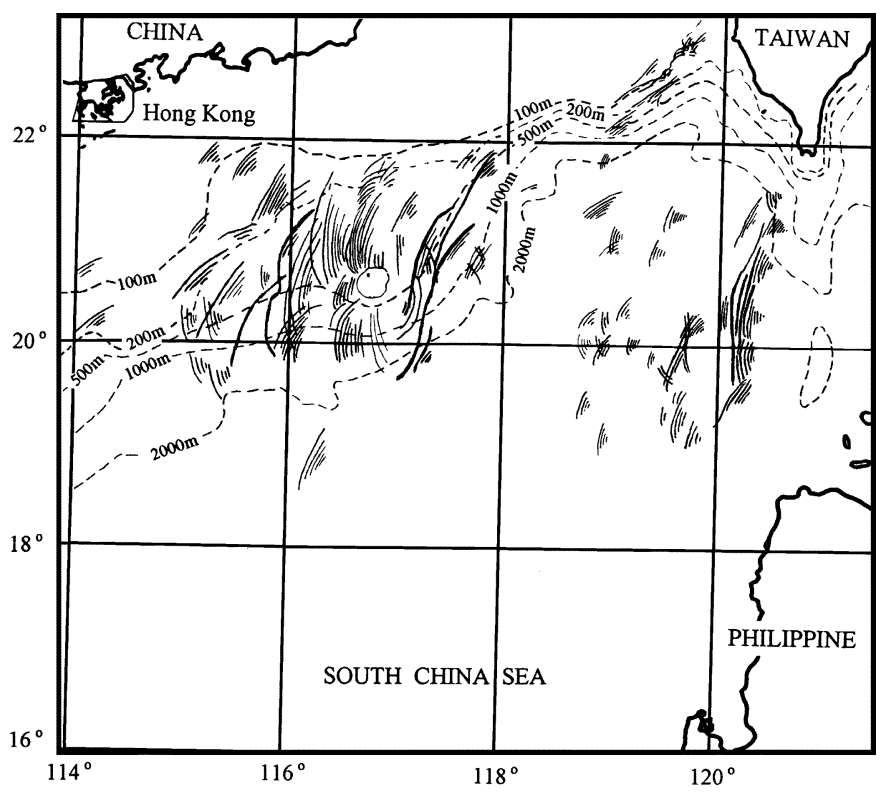

Fig. 1. Summary of the internal wave distributions in the northern SCS based on the available SAR imagery (from [24]).

With the exceptions described before, shoaling would induce a large-amplitude internal soliton breaking in the continental slope. Vlasenko and Hutter [22] used a numerical simulation to study the process of the internal soliton breaking on the continental slope. Their results showed that the internal soliton displayed some special characteristics in the current field when the wave was close to breaking. These characteristics included the soliton waveform becoming asymmetric and the time evolution of current velocity around the nodal point deformed, relative to the velocity in the uppermost and lowermost layers.

In the northern South China Sea (SCS), satellite images show that internal solitons are active [2], [13], [23], [24]. Both Ebbsemeyer et al. [24] and Bole et al. [2] found that internal solitons in the northern SCS occurred at the semidiurnal tidal frequency. They inferred that the internal soliton was generated by a point source in the Luzon Strait. Hsu et al. [25] studied historical synthetic aperture radar (SAR) images and found that the internal solitons were normally active in two regions: west of the Luzon Strait and in the continental slope of northern SCS (Fig. 1). Using the SAR images and a numerical model, Liu et al. [13] found the internal soliton west of Luzon Strait propagates westward, the length of the wave crest is approximately $200 \mathrm{~km}$, and the vertical displacement of the isopycnals is approximately $100 \mathrm{~m}$. This estimated displacement is much larger than the observations in the Andaman Sea [26], Sulu Sea [27], Georges Bank [28], Mid-Atlantic Bight [3], and the warm pool of the western equatorial Pacific [29].

However, theories and models of active solitons in the northern SCS need ground truth for validation. Field measurements, conducted as pilot studies for the Asian Seas International Acoustics Experiment (ASIAEX), were acquired during April of 1999 and 2000. Current velocity and temperature measurements from moorings are presented, analyzed, and discussed in this paper. The results not only provide ground truth for satellite images, but also provide validation for the earlier theoretical studies on the evolution and transformation of internal solitons.

This paper is organized as follows. Section II gives a general description of the measurements. The observed solitons are categorized into four types in Section III and transformation solitons are illustrated. Section IV describes the vertical structure of the solitons and presents estimates of the propagating speeds. A discussion, which includes the breaking stage of a soliton and a summary are providing in Section V.

\section{MEASUREMENTS}

\section{A. Fieldwork}

A mooring was deployed in April of 1999 and 2000 to monitor the current velocity and temperature variations in an area northeast of Tung-Sha Island, where satellite imagery showed that solitons were active. Fig. 2 shows the mooring location and design. The local water depth is $426 \mathrm{~m}$ and the mooring contained a $150-\mathrm{kHz}$ acoustic Doppler current profiler (ADCP) and a string of temperature sensors. The T-string was slack-moored above the ADCP mooring. The moorings of 1999 and 2000 were generally similar, but the ADCP depth was at $260 \mathrm{~m}$ in 1999 and $237 \mathrm{~m}$ in 2000. Two temperature-pressure recorders (TPs) were mounted at 5 and $10 \mathrm{~m}$, respectively, beneath the ADCP in 1999. In 2000, one SEACAT conductivity-temperature-depth (CTD) replaced the two TP recorders and additional vector-averaging current meters (VACMs) were mounted at 325 and $395 \mathrm{~m}$. The pressure data were used to correct the velocity data for mooring motion. The length of each deployment was about $10 \mathrm{~d}$ in 1999 and $22 \mathrm{~d}$ in 2000. The ADCP sampling intervals were $30 \mathrm{~s}$ in 1999 and $60 \mathrm{~s}$ in 2000.

With the exception of the 2000 deployment, when the VACM at $325 \mathrm{~m}$ ran out of memory $11 \mathrm{~d}$ after deployment, the current velocity measurements were quite successful. The mooring platform was generally stable, but had large vertical excursions when a soliton passed through. The maximum vertical excursion was over $40 \mathrm{~m}$; however, the tilt sensor data indicated that the ADCP generally remained upright enough to function properly. Depth corrections have been made on the measured current velocity. The current velocity measurements at several uppermost depths have some data gaps and no interpolation was performed. Temperature measurements, however, were not as successful. The string of temperature sensors ran out of memory $6 \mathrm{~d}$ after deployment in 1999 and was lost during 2000. The available data is summarized in Table I.

\section{B. Observations From the 1999 Deployment}

Fig. 3 shows the east $(U)$ and north $(V)$ component current velocity at 30,130 , and $240 \mathrm{~m}$ and temperature $(T)$ at 60,120 , 210 , and $265 \mathrm{~m}$ during 1999. The subtidal current velocity was generally weak; the diurnal and semidiurnal tidal currents were dominant instead. The diurnal tide dominated in the beginning of the record while the semidiurnal tide gradually became more pronounced. The most remarkable feature was that both $U$ and $V$ had a number of large spike-like fluctuations that started April 15 , when the semidiurnal tidal current velocity was large. A soliton is a reasonable explanation for such spike-like fluctuations. The leading soliton caused the primary large fluctuation, 

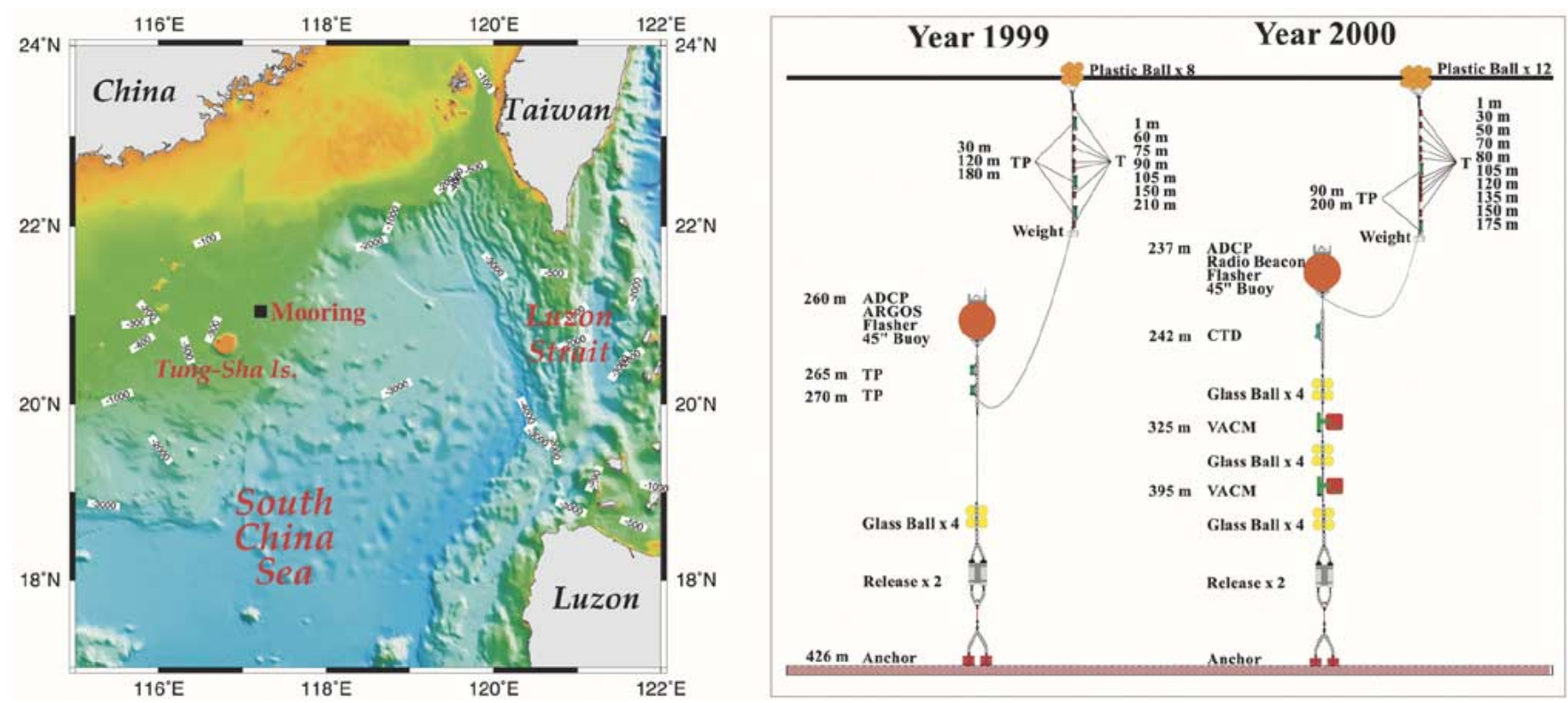

Fig. 2. Locator map and engineering drawings of the ASIAEX pilot study moorings. The left panel shows the mooring location $\left(21^{\circ} 2.8^{\prime} \mathrm{N}, 117^{\circ} 13.2^{\prime} \mathrm{E}\right.$, squared mark) and surrounding bathymetry. The left panel shows the schematic drawings of the moorings in 1999 and 2000.

TABLE I

SUMMARY OF THE MOORING INFORMATION

\begin{tabular}{lllll}
\hline $\begin{array}{l}\text { Instrument } \\
\text { Depth, } \mathrm{m}\end{array}$ & $\begin{array}{l}\text { Instrument } \\
\text { Type }\end{array}$ & $\begin{array}{l}\text { Record } \\
\text { Dates }\end{array}$ & $\begin{array}{l}\text { Sampling } \\
\text { Rate, min }\end{array}$ & $\begin{array}{l}\text { ADCP Recording } \\
\text { Depth, } \mathrm{m}\end{array}$ \\
\hline Year 1999 & & & & \\
1 & $\mathrm{~T}$ & April $9 \sim 14$ & 1 & \\
30 & TP & April $9 \sim 14$ & 1 & \\
60 & $\mathrm{~T}$ & April $9 \sim 14$ & 1 & \\
75 & $\mathrm{~T}$ & April $9 \sim 14$ & 1 & \\
90 & T & April $9 \sim 14$ & 1 & \\
105 & T & April $9 \sim 14$ & 1 & \\
120 & TP & April $9 \sim 14$ & 1 & \\
150 & T & April $9 \sim 14$ & 1 & \\
180 & TP & April $9 \sim 14$ & 1 & \\
210 & T & April $9 \sim 14$ & 1 & \\
260 & ADCP & April $9 \sim 18$ & 0.5 & \\
265 & TP & April $9 \sim 18$ & 0.5 & \\
270 & TP & April $9 \sim 18$ & 0.5 & \\
Year 2000 & & & & \\
237 & ADCP & April $9 \sim 30$ & 1 & \\
242 & CTD & April $9 \sim 30$ & 1 & \\
325 & VACM & April $9 \sim 19$ & 1 & \\
395 & VACM & April $9 \sim 30$ & 1 & \\
\hline
\end{tabular}

while the sequential solitons caused smaller fluctuations. The interval between two leading solitons was generally around $12 \mathrm{~h}$. Six leading solitons were observed in this experiment. Generally, a soliton emerged when the semidiurnal tidal current velocity had westward acceleration. The soliton caused a negative surge in $U$ (westward acceleration and then deceleration) at 30 and $130 \mathrm{~m}$. This feature was reversed at $240 \mathrm{~m}$, where the current velocity had positive surge (eastward acceleration and then deceleration). The maximum westward current velocity was over $200 \mathrm{~cm} / \mathrm{s}$ at $30 \mathrm{~m}$ and the maximum eastward velocity was over $100 \mathrm{~cm} / \mathrm{s}$ at $240 \mathrm{~m}$. The fact that $U$ was out of phase between the upper and lower water column demonstrates that the soliton was principally the first baroclinic mode.

Similar to $U, V$ had weak subtidal current velocity with the diurnal and semidiurnal tidal currents more apparent. The amplitudes of the spike-like fluctuations were much smaller than in $U$ and the maximum amplitude was less than $40 \mathrm{~cm} / \mathrm{s}$. $V$ at depth had either acceleration/deceleration or deceleration/acceleration evolution when the soliton passed by. The fluctuations at 30 and $130 \mathrm{~m}$ were consistently out of phase with the fluctuations at $240 \mathrm{~m}$. These results for the $U$ and $V$ components indicate that the first mode baroclinic soliton essentially propagated westward, but could deflect slightly to either the north or south.

Unlike the current velocity, $T$ had large semidiurnal and small diurnal variations. This result implies that the semidiurnal and diurnal tides were mainly baroclinic and barotropic, respectively. Although most of the $T$ sensors ran out of memory before April 15, the two TPs at 265 and $270 \mathrm{~m}$, beneath the $\mathrm{ADCP}$, recorded the temperature variation over the entire 


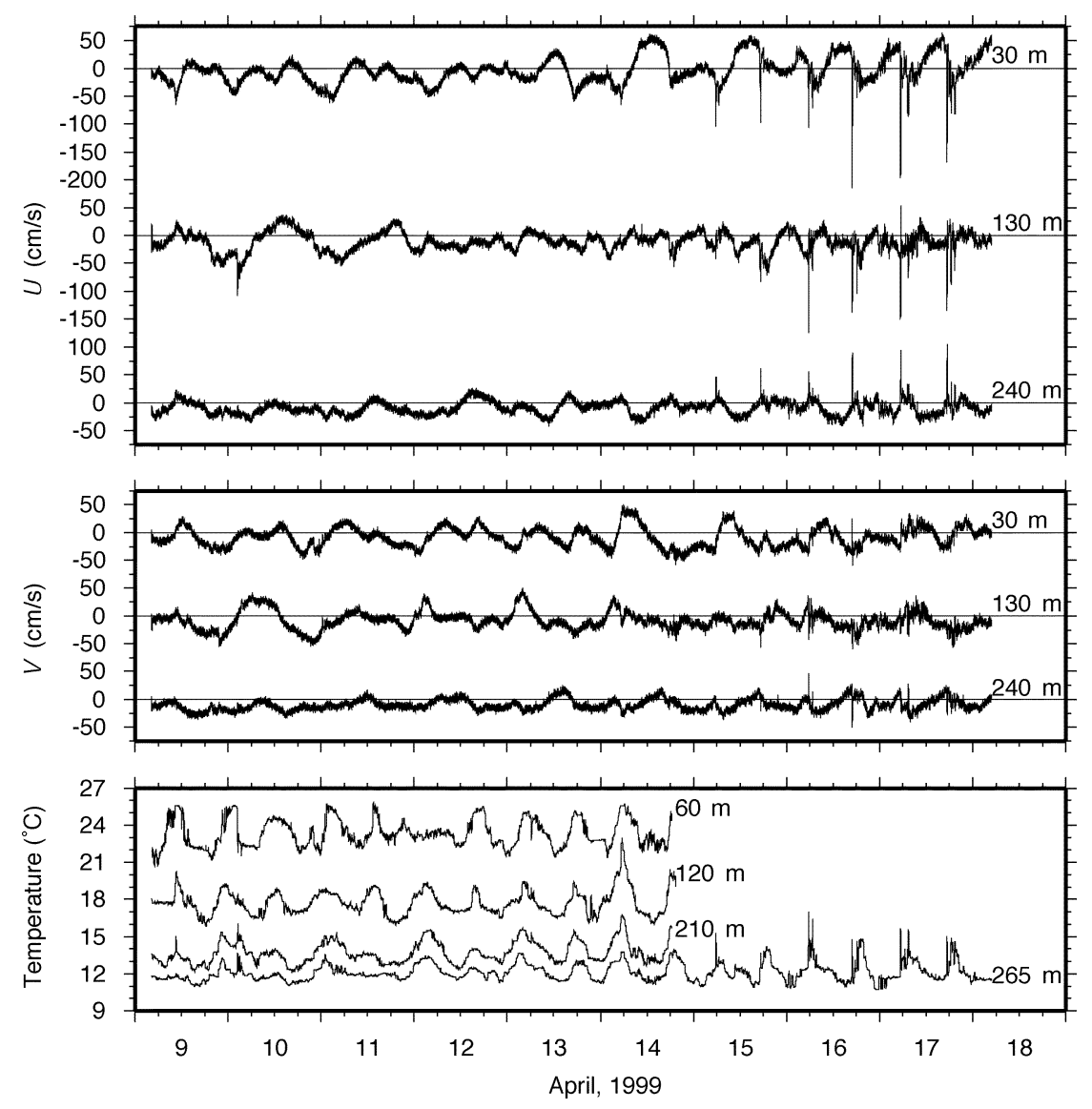

Fig. 3. Time series of the east $(U)$ and north $(V)$ velocity components (top and middle panels) and temperature $(T)$ (bottom panel) during April 1999 . The velocities at 30 and $130 \mathrm{~m}$ are from the ADCP and at $240 \mathrm{~m}$ from the VACM. The temperature $(T)$ time series are from a 60-, 120-, 210-, and 265-m depth.

duration. $T$ also had spike-like fluctuations, which occurred simultaneously with $U$ 's fluctuations. The maximum amplitude of the $T$ fluctuation at $265 \mathrm{~m}$ was over $3{ }^{\circ} \mathrm{C}$. Although the large $T$ fluctuation generally coincided with a large $U$ fluctuation, they were not in proportion. The spike-like fluctuation of $T$ first increased and then decreased. This indicates the soliton is a depression wave.

A small spike-like fluctuation occurred on April 10, which had quite different characteristics than the other fluctuations; it had a westward current velocity surge at $130 \mathrm{~m}$, but the $U$ fluctuations at 30 and $240 \mathrm{~m}$ were minimal. Corresponding to the $U$ fluctuation, $T$ had a negative surge (decrease first, then increase) at $60 \mathrm{~m}$, while it had a positive surge (increase first, then decrease) at 210 and $265 \mathrm{~m}$. Its fluctuation at $120 \mathrm{~m}$ was vague. The second baroclinic mode soliton can account for such fluctuations; this is discussed later in detail.

\section{Observations From the 2000 Deployment}

The measurements in 2000 provided a longer record than in 1999 , but $T$ was only obtained at 242,325 , and $395 \mathrm{~m}$. The thermistor chain in the upper water column was lost. Fig. 4 shows $U$ and $V$ at $30,130,210,325$, and $395 \mathrm{~m}$ and the $T$ at 242, 325, and $395 \mathrm{~m}$ during April 2000. Thirty-five leading solitons were recorded over the entire period, April 9-30. The solitons in
2000 had similar features to the 1999 events, but they also had some noticeable differences. Similarities included the soliton exhibiting large amplitude in $U$ and small amplitude in $V$. This caused the current to primarily accelerate/decelerate westward and eastward in the upper and lower water column, respectively, and caused temperature to fluctuate. The solitons behaved as first baroclinic mode depression waves. The largest westward current was around $240 \mathrm{~cm} / \mathrm{s}$ at $30 \mathrm{~m}$ and the largest eastward current was around $150 \mathrm{~cm} / \mathrm{s}$ at $395 \mathrm{~m}$. The largest $T$ fluctuation at $242 \mathrm{~m}$ was around $11{ }^{\circ} \mathrm{C}$. In general, the solitons appeared with semidiurnal tides. The time interval between two leading solitons was around $12 \mathrm{~h}$, but varied slightly. The most notable difference of the solitons between the 1999 and 2000 observations was that the solitons only occurred during the spring tide in 1999, while it occurred over the entire period of observation in 2000. However, solitons were found irregularly and had small amplitude during the neap tide.

\section{CTD Profiles}

Fig. 5 shows the temperature and density profiles obtained from the 4 CTD casts performed before the mooring deployments after mooring recoveries in 1999 and 2000, respectively. The two profiles made before the deployments were generally similar, but the one for 1999 shows a relatively thicker mixed layer and stronger stratification. However, this difference could 


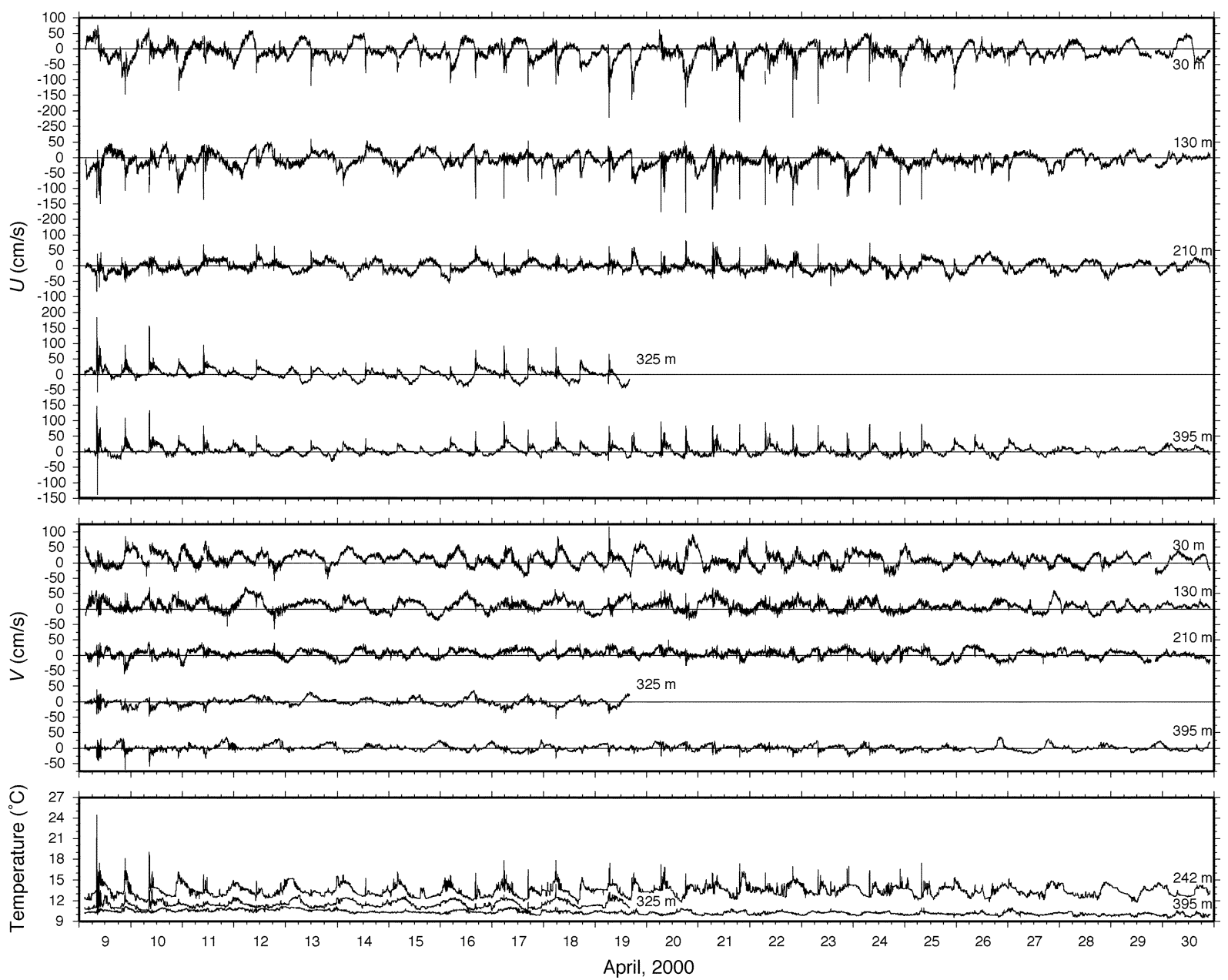

Fig. 4. Time series of the east $(U)$ and north $(V)$ velocity components (top and middle panels) and temperature $(T)$ (bottom panel) during April 2000. The velocities at 30, 130, and $210 \mathrm{~m}$ are from the ADCP and at 325 and $395 \mathrm{~m}$ from the VACM. The temperature $(T)$ time series are from 242-, 325-, and 395-m depths.

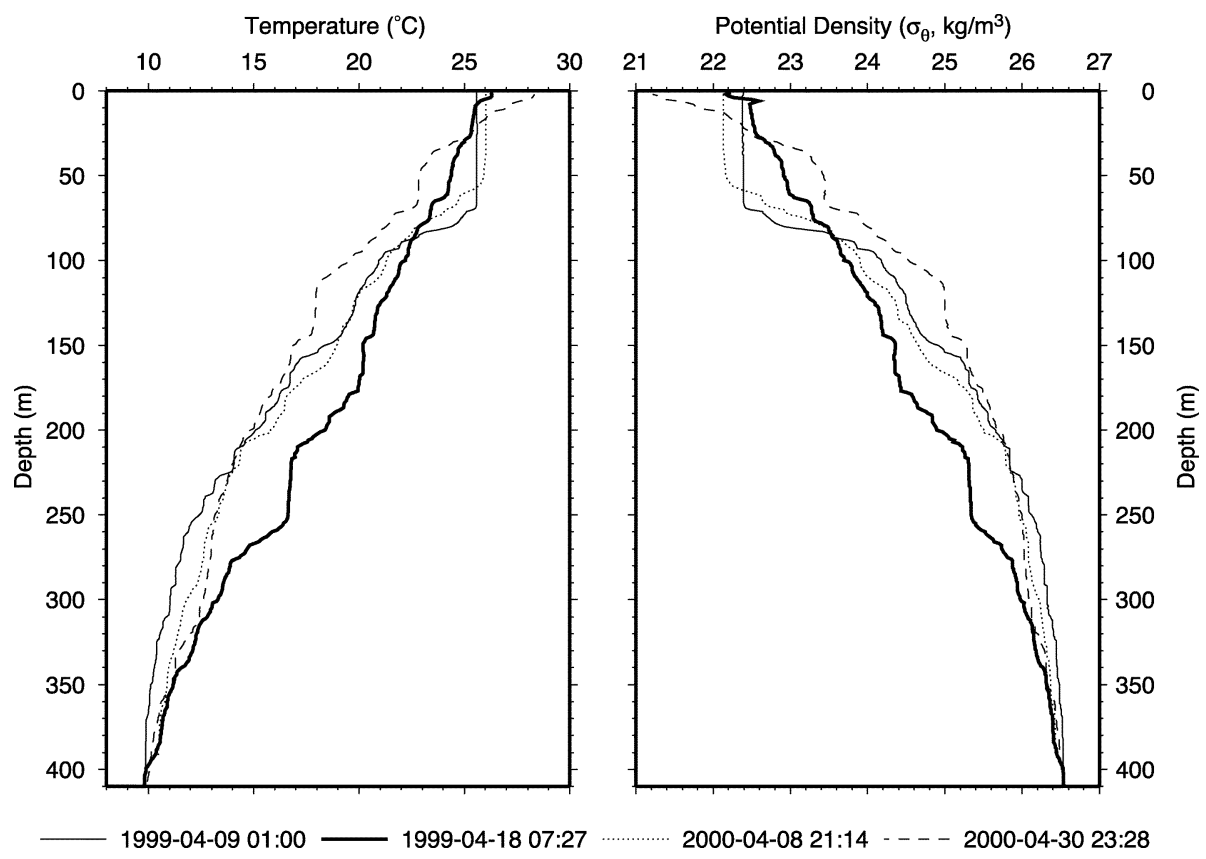

Fig. 5. Vertical profiles of temperature (left panel) and potential density (right panel) near the mooring location. The thin, bold, dotted, and dashed lines indicate the profiles, which were measured before mooring deployments and after mooring recoveries in 1999 and 2000, respectively. 
be related to a fluctuation such as an internal tide. The mixed layer vanished after the mooring recovery in both 1999 and 2000. The disappearance of the mixed layer in 1999 after recovery could be related to a soliton that we observed passing the research vessel immediately before the CTD cast. The large vertical motion caused by the soliton not only made the mixed layer vanish, but also made stratification weaker. In 2000, the mixed layer also vanished, but the stratification remained strong. The upwelling, caused by the internal tide, could raise the isotherm and make the mixed layer shallower or even disappear. This conjecture is supported by the moored temperature data recorded up to $1 \mathrm{~h}$ before the CTD measurement that indicates that upwelling was ongoing. The water stratification between the two years is similar, however, as evidenced by the two CTD profiles before the mooring deployments.

\section{Evolution OF Solitons}

The time evolution of 41 first-mode leading solitons observed during 1999 and 2000 were generally similar. Nevertheless, each soliton had its own characteristics. The 41 solitons can be categorized into four types. The first type of soliton had relatively small amplitude and could be generally described by the $\mathrm{KdV}$ equation. It is referred to as a $\mathrm{KdV}$ soliton hereafter, following Remoissenet [30]. Two other types are solitons that were observed in the transition zone from depression to elevation waves, with one type before and the other close to the turning point. These solitons usually had large amplitude. These three soliton types are first baroclinic-mode depression waves. The second baroclinic-mode soliton is categorized to the fourth type.

\section{A. KdV Soliton}

The KdV soliton generally occurred around the neap tide period. One that appeared at 1315 GMT on April 14, 2000 is used as an example to demonstrate the $\mathrm{KdV}$ soliton. Fig. 6 shows the time-depth contours of $U$ and $V$ from 30 to $210 \mathrm{~m}$ and time series at 325 and $395 \mathrm{~m}$. The time series of $T$ at 242, 325, and $395 \mathrm{~m}$ are also shown. When the soliton arrived, $U$ accelerated westwardly in the upper water column and eastwardly in the lower water column. The maximum westward speed was over $80 \mathrm{~cm} / \mathrm{s}$ and the maximum eastward speed slightly exceeded $50 \mathrm{~cm} / \mathrm{s}$. The time evolution at a depth is symmetric and could be described well by the square of a hyperbolic secant curve, which is proportional to a solution of the $\mathrm{KdV}$ equation [31]. The locus of the zero crossing of $U$ was close to $130 \mathrm{~m}$. No phase lag was found between the maxima of westward and eastward speed. This result indicates that the soliton is the first baroclinic mode. The $V$ component exhibited smaller wave-induced fluctuations since the KdV soliton primarily propagated to the west.

$T$ was nearly constant before and after the soliton arrived. With the emergence of the soliton, $T$ went through an increase/decrease evolution of amplitude around $2.5^{\circ} \mathrm{C}$ at $242 \mathrm{~m}$, less than $1^{\circ} \mathrm{C}$ at $325 \mathrm{~m}$ and was nondiscernible at $395 \mathrm{~m}$. The temperature increasing first and then decreasing indicates that the soliton was a depression wave. The time evolution of $T$ also was well described by the square of a hyperbolic secant curve.
No noteworthy sequential soliton behind the leading $\mathrm{KdV}$ soliton was found. The KdV soliton is the first baroclinic modedepression wave that generally satisfies the $\mathrm{KdV}$ solution and, therefore, would have only weak nonlinear effects.

In summary, the KdV solitons could be described well by a squared-hyperbolic-secant profile, as obtained from an analytical solution of the KdV equation. They generally occurred around the neap tide period and primarily propagated to the west. The time evolutions of current speed and temperature were symmetric. The current directions in the upper and lower layers were westward and eastward, respectively, and the nodal point was approximately $130 \mathrm{~m}$. No time lag between the maximum current speeds in the upper and lower layer was found. The KdV soliton represents the first baroclinic mode depression wave.

\section{B. Solitons in the Transition Zone Before the Turning Point}

Most of the leading solitons observed during the experiments of 1999 and 2000 were of this type. They were typically observed during the spring tidal period. The characteristics of this type of soliton are demonstrated using a soliton, which emerged around 1911 GMT on April 21, 2000 (Fig. 7). Similar to the $\mathrm{KdV}$ soliton, this type of soliton also caused $U$ to accelerate/decelerate westwardly and eastwardly in the upper and lower water column, respectively, but caused only a small fluctuation in $V$. The temperature displayed an increasing then a decreasing fluctuation. This type of soliton also was a first baroclinic mode-depression wave, propagating primarily westward.

The differences between the fluctuations caused by the $\mathrm{KdV}$ and the type- 2 soliton are noteworthy. The type- 2 soliton had much larger amplitude with maximum westward and eastward speeds around 240 and $90 \mathrm{~cm} / \mathrm{s}$, respectively. The time evolution of $U$ at a depth in the upper and lower layers still was near the square of a hyperbolic secant curve, but was skewed slightly. The $U$ acceleration in the upper layer (or deceleration in the lower layer) was more rapid in the front than the rear of the soliton. At the middle depths, the time evolution was seriously deformed and could not be represented by a single square of a hyperbolic secant curve. The $U$ component accelerated westward, then eastward, and then westward again. The timing of the maximum speed (eastward or westward) varied with depth The time evolution at the middle depths was poorly correlated with the evolution at either the uppermost or lowermost depths.

The present soliton also caused $T$ at $242 \mathrm{~m}$ to increase then decrease, but the fluctuation was asymmetric with a sharper gradient at the leading edge than at the back side. The amplitude of the temperature fluctuation at $242 \mathrm{~m}$ was around $4.5{ }^{\circ} \mathrm{C} \mathrm{A}$ small kink developed behind the leading soliton. After the kink, the tail of the soliton was not flat. Several fluctuations cumulatively created a temperature higher than the initial state. Similar fluctuations in the tail were also found in $U$ and even in $V$. These fluctuations were related to the sequential solitons that often emerged behind the leading soliton.

Due to the complexity of the time evolution of $U$ at middle depths, the locus of the nodal point could be only roughly estimated around $150 \mathrm{~m}$. The nodal point was shallower than half the water depth $(426 \mathrm{~m})$. According to the two-layer fluid theory of Liu et al. [13], the soliton has not yet reached the turning point. However, the wave shape has been transformed, including 


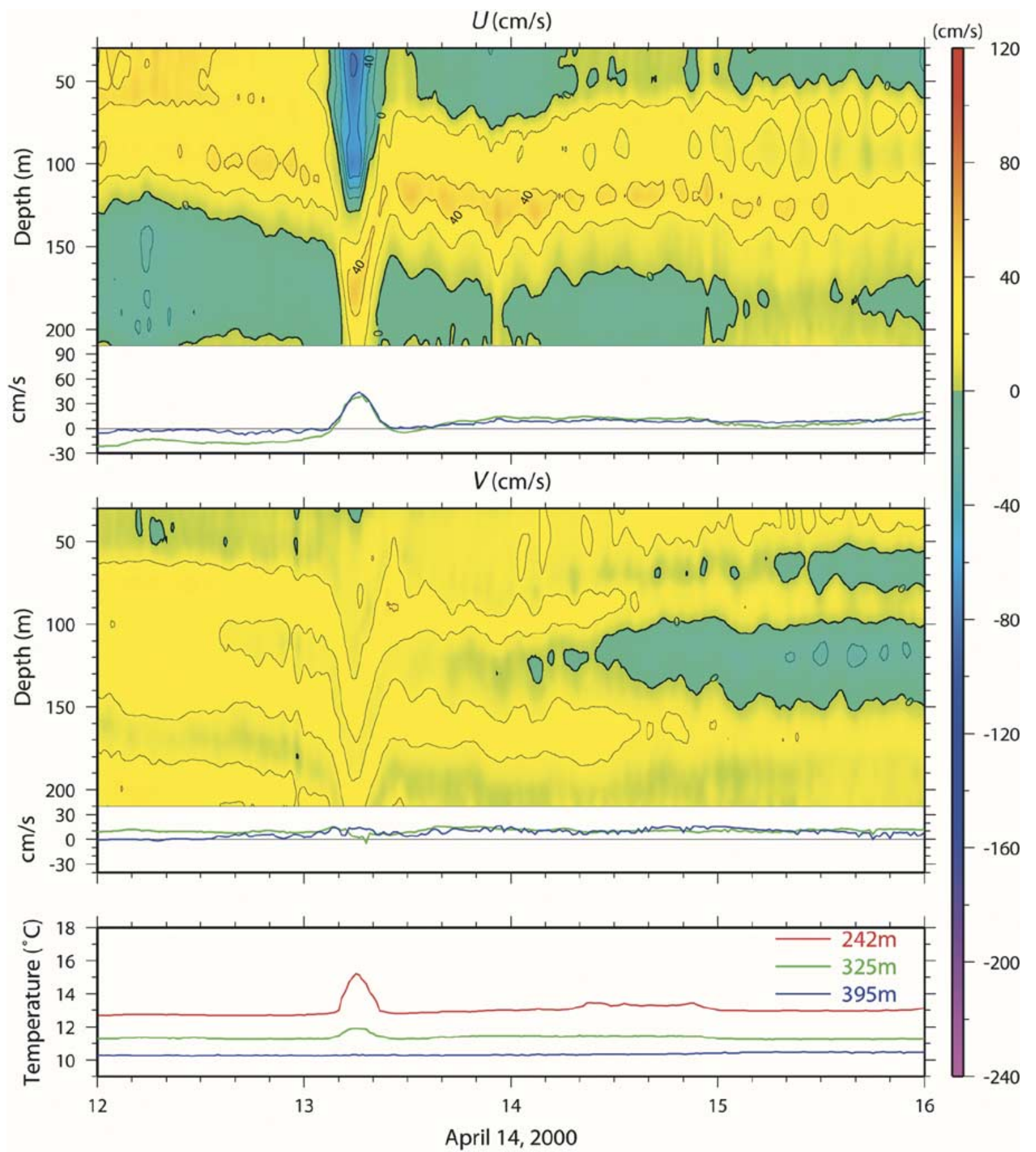

Fig. 6. Soliton passage on April 14, 2000, as observed by the ASIAEX pilot study mooring. From top to bottom: Contours of the east ( $U$ ) velocity component between $30-210 \mathrm{~m}$ as a function of depth and time; the $U$ time series at 325 and $395 \mathrm{~m}$; contours of the north $(V)$ velocity component between $30-210 \mathrm{~m}$ as a function of depth and time; the $V$ time series at 325 and $395 \mathrm{~m}$; and the temperature $(T)$ time series at 242,325 , and $395 \mathrm{~m}$. The contour interval is $20 \mathrm{~cm} / \mathrm{s}$ with the zero-contour in bold. The red, green, and blue lines indicate the time series at 242, 325, and $395 \mathrm{~m}$, respectively.

developing a kink behind the main pulse of the soliton and increasing $T$ on the soliton tail. Therefore, this type of soliton is categorized as in the transition zone but before reaching the turning point [14], [15].

The shoaling effect may be the primary factor in the development of a kink after the main pulse of a soliton. Higher order nonlinear effects further enhance the kink amplitude [15], [20]. Grimshaw et al. [14] inferred that the kink is the first stage in the transformation from a depression to an elevation soliton. The feature of an increase of $T$ on the tail of a soliton has been dis- cussed by Johnson [19], Grimshaw et al. [14], and Small [15], where the increase in $T$ was attributed to vertical displacement (downward) of the thermal structure of the water column. It is due to the fact that when bottom friction induces the soliton on its own, it does not conserve mass (though it does conserve energy) and the tail compensates for this. The phenomena of the asymmetry of the soliton time evolution and the complexity of the time evolution of $U$ at middle depths may be related to the soliton being close to the breaking status [22]. More discussion is provided later. 


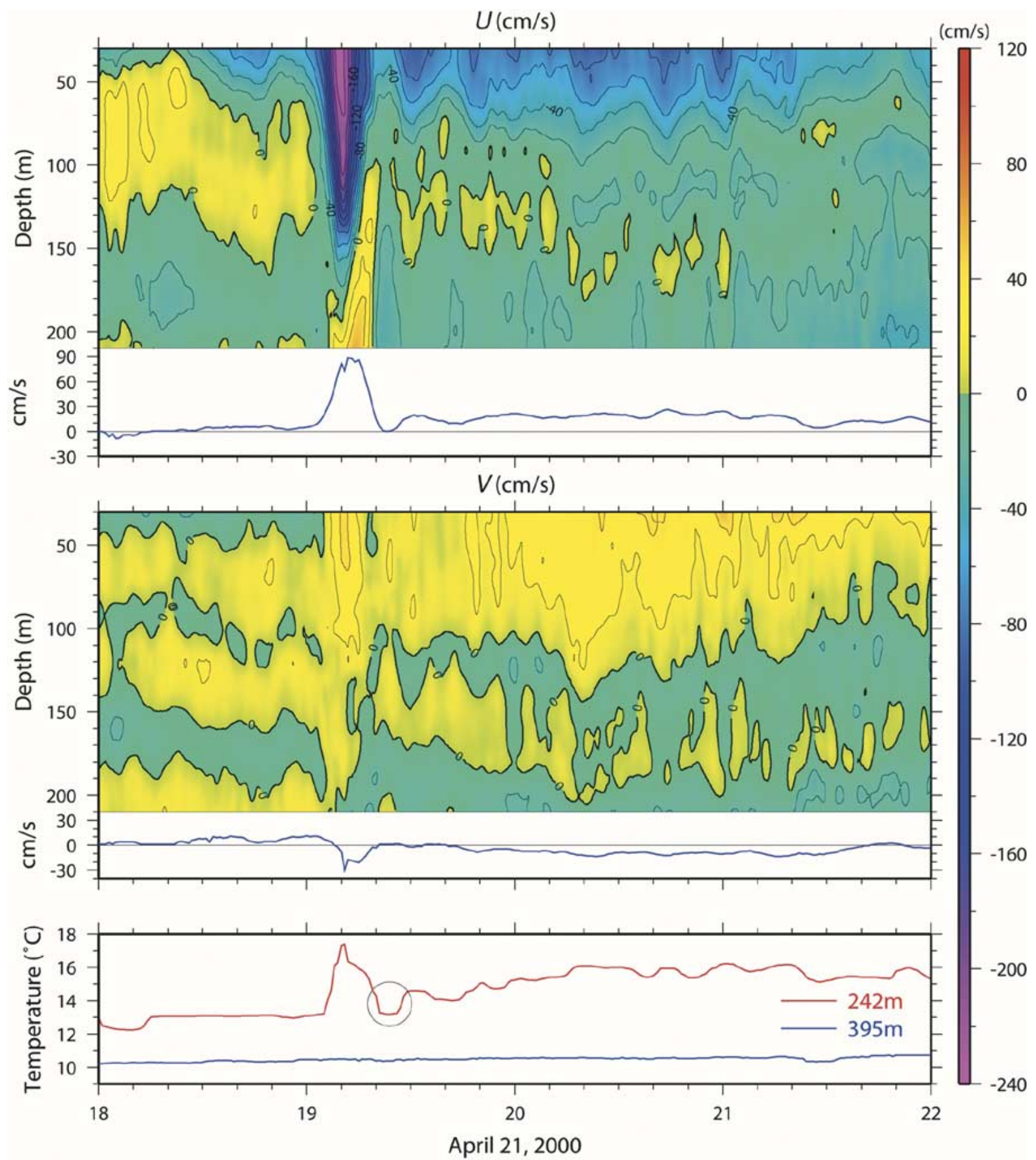

Fig. 7. Same as Fig. 6 except for April 21, 2000. The open circle indicates the "kink" phenomenon.

In summary, this type of soliton was in the transition zone, but before reaching the turning point. It was typically seen during the spring tidal period and its amplitude was much larger than the KdV soliton. The type- 2 soliton was a first baroclinic modedepression wave and primarily propagated to the west. The time evolution of $U$ in either the upper or lower layer was still near a squared-hyperbolic-secant profile, but it was skewed slightly. At the middle depths, the time evolution of $U$ was deformed seriously; it cannot be represented by a single squared-hyperbolic-secant curve. The evolution of $T$ was asymmetric with a sharper increase than decrease. A small kink and a number of fluctuations followed the main pulse and the resulting temperature was higher than its initial state.

\section{Soliton in the Transition Zone Close to the Turning Point}

Only one observed soliton is categorized as this type. It is shown in Fig. 8 and occurred around 0820 GMT April 9, 2000. The ADCP velocity in the upper $130 \mathrm{~m}$ had a data gap of several minutes during the peak of the soliton. The vertical excursion of the ADCP (about $43 \mathrm{~m}$ ) was fairly large. The tilt sensor showed 


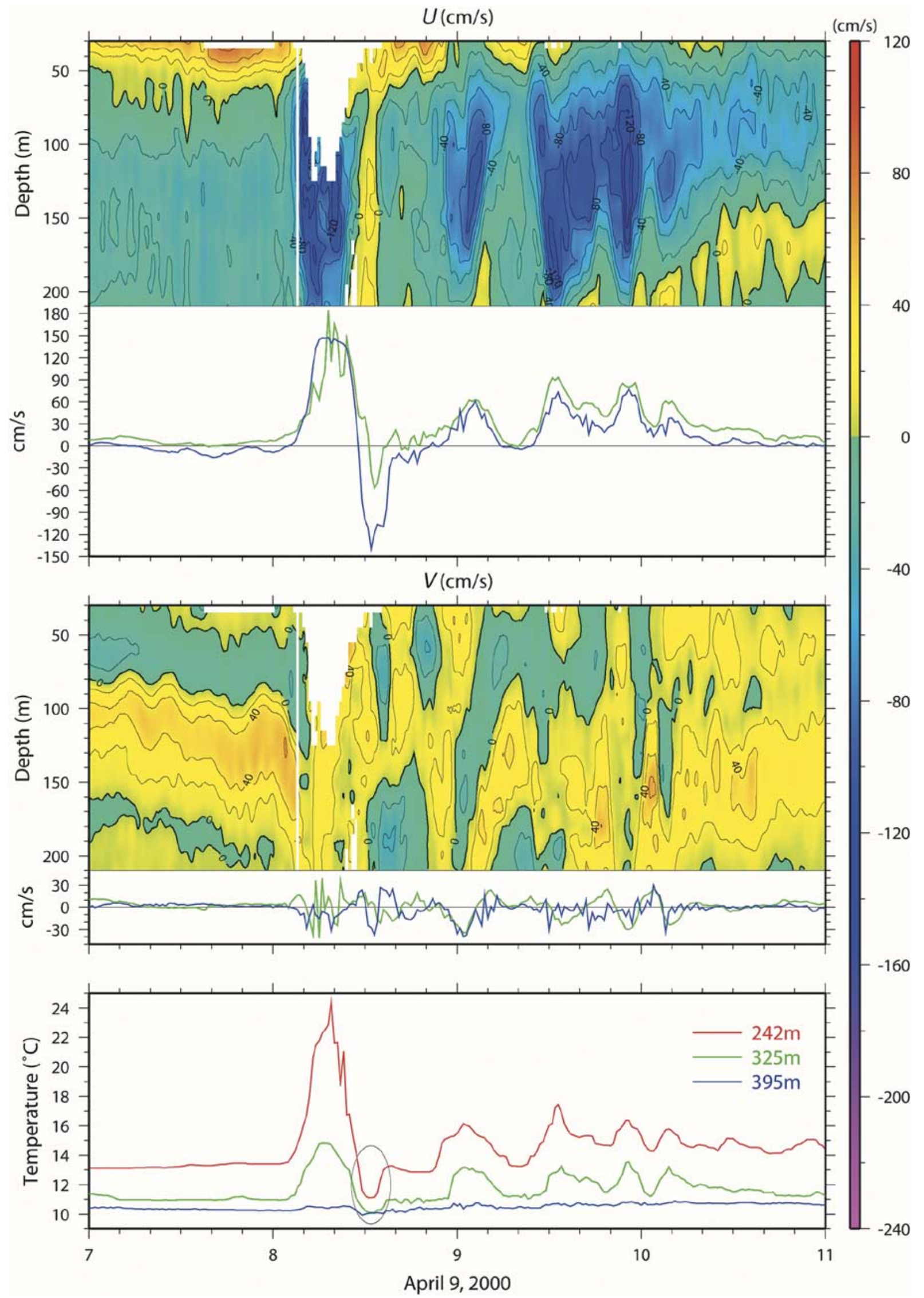

Fig. 8. Same as Fig. 6, except for April 9, 2000. The open ellipse indicates the "kink" phenomenon. 


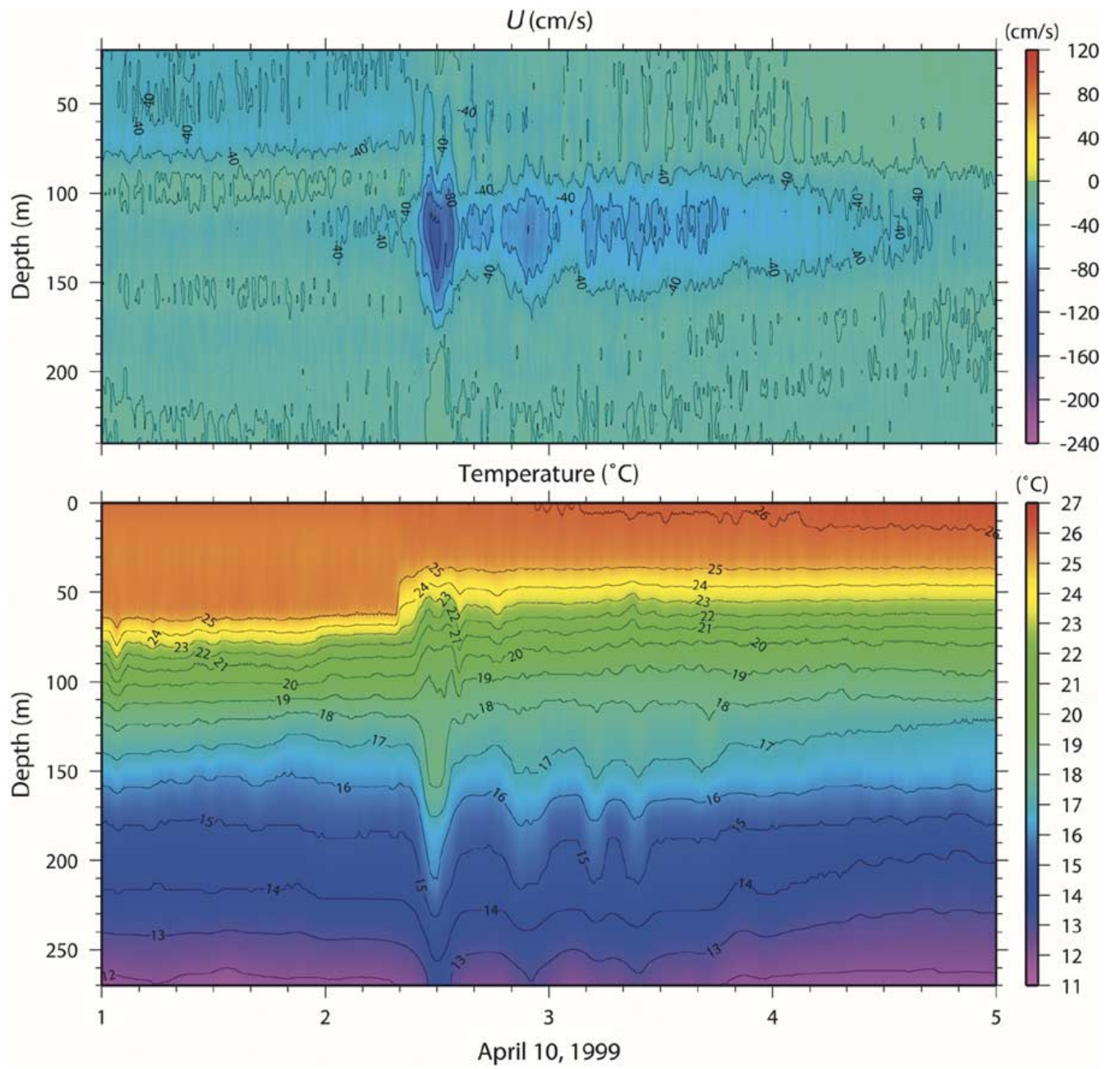

Fig. 9. Color contour plots of the eastward velocity component (top) and temperature (bottom) at the ASIAEX mooring during April 10, 1999. The contour intervals are $20 \mathrm{~cm} / \mathrm{s}$ for $U$ and $1^{\circ} \mathrm{C}$ for $T$.

that the tilt of the ADCP was small. This indicates that the vertical excursion is probably not responsible for the data gap. The exact reason is unknown.

Similar to the type-2 soliton, the $U$ component had a westward surge in the upper layer, indicated by the ADCP measurement between 130 and $210 \mathrm{~m}$, and an eastward surge in the lower layer, shown by the VACM measurement at 325 and $395 \mathrm{~m}$ as the soliton passed by. The maximum amplitude of the eastward surge was close to $150 \mathrm{~cm} / \mathrm{s}$, but the maximum amplitude of the westward surge is unknown. The impact of the soliton on $V$ was small. $T$ also displayed an increase/decrease fluctuation as the soliton passed through. Clearly, this type of soliton is a first baroclinic mode-depression wave and it primarily propagated to the west. On the tail of the main pulse of the soliton, several fluctuations (or sequential solitons) were seen and $T$ increased.
Although there are similarities, some differences between the type- 2 and type- 3 solitons are noteworthy. The type-3 soliton caused a much larger $T$ fluctuation, over $11^{\circ} \mathrm{C}$ at $242 \mathrm{~m}$ and over $4{ }^{\circ} \mathrm{C}$ at $325 \mathrm{~m}$. The eastward surge had much larger amplitude in the type- 3 than in the type- 2 soliton. The locus of the nodal point is inferred to be between 210 and $325 \mathrm{~m}$, much deeper than with the type- 2 soliton. The most pronounced difference is that an opposite surge developed immediately behind the main pulse. This aspect is particularly apparent considering the fluctuations of $U$ and $T$ at $395 \mathrm{~m}$.

In this type of soliton, the zero crossing of $U$ is very possibly close to half of the water depth, so the soliton could be close to the turning point in accordance with the two-layer fluid theory [13]. Following the main pulse of the soliton, the opposite surge made $T$ lower than the initial state. This feature was also shown in the results of numerical and theoretical experi- 
ments [14], [15] when the wave was close to the turning point. The opposite surge could be an embryo of an elevation soliton. Therefore, this soliton is categorized to a soliton in the transition zone, but close to the turning point.

In summary, this type of soliton was in the transition zone but beyond the turning point. Here, characteristics are similar to the last type of soliton, but with a few notable differences. The amplitude of this type is larger, especially in the temperature fluctuation. The locus of the nodal point is much deeper than with the last type of soliton. Finally, following the main pulse of the soliton, temperature was lower than the initial state.

\section{Second Baroclinic Mode Soliton}

A type-4 second baroclinic mode soliton, (Fig. 9) was observed on 0230 GMT April 10, 1999. Only one wave of this type was observed. Compared to the first-mode soliton, the amplitude of the velocity fluctuations in both $U$ and $V$ components were small. The mode two soliton created a "bulge" in the thermocline centered close to a 120 -m depth when it went by. The $U$ component had a westward acceleration/deceleration evolution between 80 and $180 \mathrm{~m}$ and an opposite evolution below 180 and above $80 \mathrm{~m}$. The temperature decreased/increased above 120 and increased/decreased below $120 \mathrm{~m}$. These $T$ and $U$ vertical profiles fit the theoretical model for a second baroclinic mode soliton [3]; no sequential solitons were found behind it. There were indiscernible variations in $V$ when the soliton emerged. This second mode soliton also propagated primarily to the west.

\section{ANALYSIS}

For a two-dimensional (2-D) soliton, its horizontal and vertical motion can generally be treated individually. The variables are expressed as

$$
\begin{aligned}
u & =\sum_{n} u_{n}(x, t) q_{n} F_{n}(z) \\
w & =\sum_{n} w_{n}(x, t) W_{n}(z) \\
\eta & =\sum_{n} \eta_{n}(x, t) W_{n}(z)
\end{aligned}
$$

where $t, x$, and $z$ denote the time and east and vertical directions, respectively; $u$ and $w$ are horizontal and vertical current velocity, respectively; and $\eta$ is the vertical displacement. $F_{n}(z)$ and $W_{n}(z)$ represent the vertical structure of horizontal and vertical motion, respectively. The modal coefficients are $u_{n}, w_{n}$, and $\eta_{n}$ and $q_{n}$ is a normalizing factor. Assuming that the motion is linear, hydrostatic, frictionless, and satisfies the Boussinseq approximation, the governing equation for the vertical velocity $W_{n}(z)$ on a $f$ plane is [32]

$$
\frac{d^{2} W_{n}}{d z^{2}}+\frac{N^{2}(z)-\sigma^{2}}{c_{n}^{2}} W_{n}=0 .
$$

Here, $c_{n}$ is linear phase speed, $\sigma$ is wave frequency, and $N$ is the buoyancy frequency that is a function of $z$ only. The vertical modes of horizontal and vertical motions are related by

$$
F_{n}=\frac{d W_{n}}{d z}
$$

The normalizing factor $q_{n}$ is obtained from

$$
\frac{1}{H} \int_{-H}^{0} F_{n}^{2} d z=\frac{1}{q_{n}^{2}}
$$

where $H$ is local water depth (426 m).

The KdV equation, which includes a quadratic nonlinear term, is commonly used to describe the horizontal waveform of $\eta_{n}$ [3]

$$
\frac{\partial \eta_{n}}{\partial t}+c_{n} \frac{\partial \eta_{n}}{\partial x}+\alpha_{n} \eta_{n} \frac{\partial \eta_{n}}{\partial x}+\beta_{n} \frac{\partial^{3} \eta_{n}}{\partial x^{3}}=0
$$

where the parameters of $\alpha_{n}$ and $\beta_{n}$ are

$$
\begin{aligned}
& \alpha_{n}=\frac{3 c_{n} q_{n}^{2}}{2 H} \int_{-H}^{0} F_{n}^{3} d z \\
& \beta_{n}=\frac{c_{n} q_{n}^{2}}{2} .
\end{aligned}
$$

Then, $\eta_{n}$ is

$$
\begin{aligned}
\eta_{n} & =\eta_{0, n} \operatorname{sech}^{2}\left(\frac{x-C_{n} t}{\Delta_{n}}\right) \\
\Delta_{n} & =\sqrt{\frac{12 \beta_{n}}{\alpha_{n} \eta_{0, n}}} \\
C_{n} & =c_{n}+\frac{\alpha_{n} \eta_{0, n}}{3} .
\end{aligned}
$$

Here, $\eta_{0, n}$ is the amplitude, $C_{n}$ is the nonlinear phase speed, and $\Delta_{n}$ is the horizontal characteristic scale. The $\eta_{0, n}$ or $C_{n}$ increases when $\Delta_{n}$ decreases. The horizontal current velocity could also be expressed as

$$
u_{n}=u_{0, n} \operatorname{sech}^{2}\left(\frac{x-C_{n} t}{\Delta_{n}}\right)
$$

where $u_{0, n}$ is the amplitude of the horizontal current speed. The leading soliton has the largest phase speed and amplitude, but the smallest horizontal characteristic scale. It also is the steepest and has the largest nonlinear effects.

\section{A. Vertical Structures}

$N$ was estimated from three CTD measurements obtained in 1999 and 2000. The CTD cast immediately after the soliton passed was excluded from this calculation. The wave frequency $(\sigma)$ was estimated at three cycles per hour $(\mathrm{c} / \mathrm{h})$ based on the observed duration of the type-1 soliton (20 min). Using $N$ and $\sigma$ in (4) and imposing a rigid lid boundary at the surface and bottom, $W_{n}(z)$ is obtained using a trial-and-error method. The linear wave phase speeds $c_{n}$ are calculated at 127 and $57 \mathrm{~cm} / \mathrm{s}$ for the first and second baroclinic mode, respectively. $F_{n}(z)$ is obtained by taking the derivative of $W_{n}(z)$ with respect to $z$.

The calculated $F_{1}(z)$ and three observed vertical profiles of $U$, taken when the soliton reached its crest and $5 \mathrm{~min}$ before and after the crest, are used to investigate the variation of the vertical structure of the current velocity as the soliton passed. In Fig. 10, the left panel shows $F_{1}(z)$ and three vertical profiles of $U$ for the first type of soliton while the right panel shows $F_{1}(z)$ 

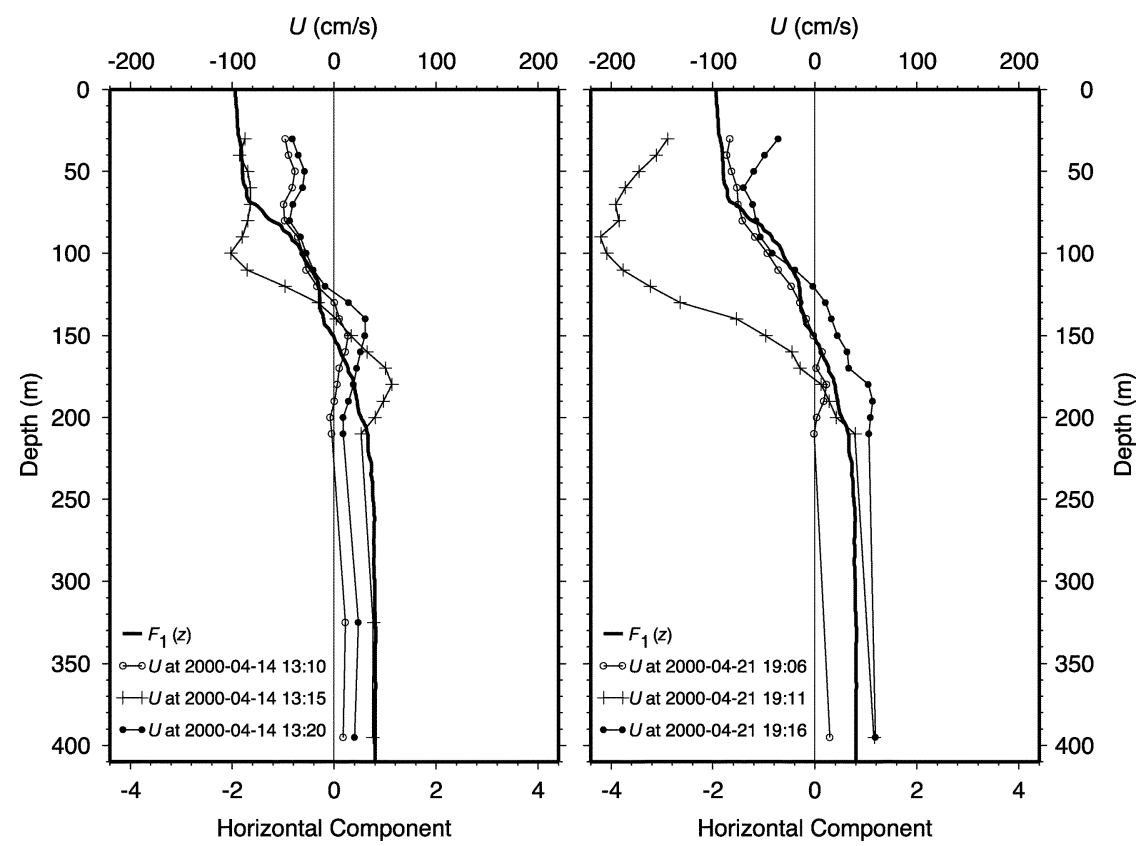

Fig. 10. Left panel: vertical profile of $F_{1}(z)$ (bold line) computed from the KdV theory and three vertical profiles of the observed $U$ velocity for the soliton that occurred on April 14, 2000. The amplitude of $F_{1}(z)$ is arbitrary. The observed $U$ has been high-pass filtered to exclude fluctuations with duration longer than 5 h. The plus sign, open circle, and solid circle lines represent when the soliton reached its crest and 5 min before and after the crest, respectively. Right panel: same as the left panel, except for the second type of soliton, which occurred on April 21, 2000.

and three vertical profiles of $U$ of the second type of soliton. $U$ has been high-pass filtered for fluctuations with a period longer than $5 \mathrm{~h}$. The nodal point for $F_{1}(z)$ is at $150 \mathrm{~m}$. The left panel shows that the soliton that occurred on 1315 GMT April 14, 2000 (Fig. 6) was a good fit for the KdV model. The locus of the nodal point of the observed type-1 soliton had a small vertical displacement; it was close to the theoretical locus of the nodal point. Nevertheless, the vertical shear of horizontal current velocity increased around the nodal point when the $\mathrm{KdV}$ soliton crest arrived. The second example, shown on the right panel of Fig. 10, occurred at 1911 GMT April 21, 2000 (Fig. 7) and is the second type of soliton. Different from the model $\mathrm{KdV}$ soliton, the observed type- 2 soliton had a nodal point that moved down, then up, with the passage of a soliton. The locus of the nodal point was deepest at the crest of the soliton and the vertical displacement of the nodal point was around $50 \mathrm{~m}$. Again, the vertical shear of the horizontal current velocity increased significantly around the nodal point with the arrival of wave crest.

Lack of current velocity data during the passage of the third type of soliton does not allow us to perform a similar study for that type. For the fourth type of soliton, the second baroclinic mode soliton, the vertical profiles of measured $U$ and estimated vertical current velocity $(W)$ were compared with the theoretical profiles of $F_{2}(z)$ and $W_{2}(z)$ (Fig. 11). As before, $U$ has been high-pass filtered to eliminate fluctuations with a period longer than $5 \mathrm{~h}$. The resulting vertical profile had little change with time (with the exception of the amplitude) so only one profile, taken at the wave crest, is shown. $W$ was estimated from the $T$ measurement using

$$
W(z) \approx-\frac{\frac{T_{t}^{h}(z)-T_{t-\Delta t}^{h}(z)}{\Delta t}}{\frac{T_{t}^{b}(z+\Delta z)-T_{t}^{b}(z)}{\Delta z}} .
$$

$T_{t}^{h}$ and $T_{t-\Delta t}^{h}$ are the 5-h high-pass temperature data, $z$ is the depth at which the temperature was recorded, $t$ is the time when the soliton reached its crest, and $\Delta t$ is $1 \mathrm{~min}$. The background temperatures $T_{t}^{b}$ are the 36-h low-pass filtered temperatures and $\Delta z$ is the depth difference between two temperature recorders. The profiles of the observations of $U$ and $F_{2}(z)$ agree well. The observed $U$ profile had zero crossings at 80 and $180 \mathrm{~m}$ while the $F_{2}(z)$ profile had nodal points around 80 and $210 \mathrm{~m}$. The difference is small. Similar good agreement is also found in $W$ and $W_{2}(z)$; their loci of nodal points have only around a $10-\mathrm{m}$ difference. Clearly, the observed second mode soliton is properly represented by the linear theory.

\section{B. Isopycnal Displacement}

The isopycnal displacement induced by internal solitons is generally estimated as

$$
\eta_{1}(t) \approx \frac{T_{t}^{h}(z)}{\frac{T_{t}^{b}(z)-T_{t}^{b}(z-\Delta z)}{\Delta z}} .
$$

During 1999, $T_{t}^{h}$ and $T_{t}^{b}$ are the 5-h high-pass and 36-h low-pass filtered temperature time series, respectively, and $z$ and $z-$ $\Delta z$ are 265 and $270 \mathrm{~m}$, the depths at which the two temperature/pressure recorders were located. The averaged amplitude of vertical isopycnal displacement $\left(\eta_{0,1, z=265}\right)$ of the six solitons observed was $74 \pm 13 \mathrm{~m}$. Theoretically, the largest isopycnal displacement would actually occur much shallower at the nodal point, around $150 \mathrm{~m}$. Using the theoretical profile $W_{1}$, the maximum isopycnal displacement $\eta_{0,1, z=150}$ is estimated as

$$
\eta_{0,1, z=150}=\eta_{0,1, z=265} \frac{W_{z=150}}{W_{z=265}}
$$




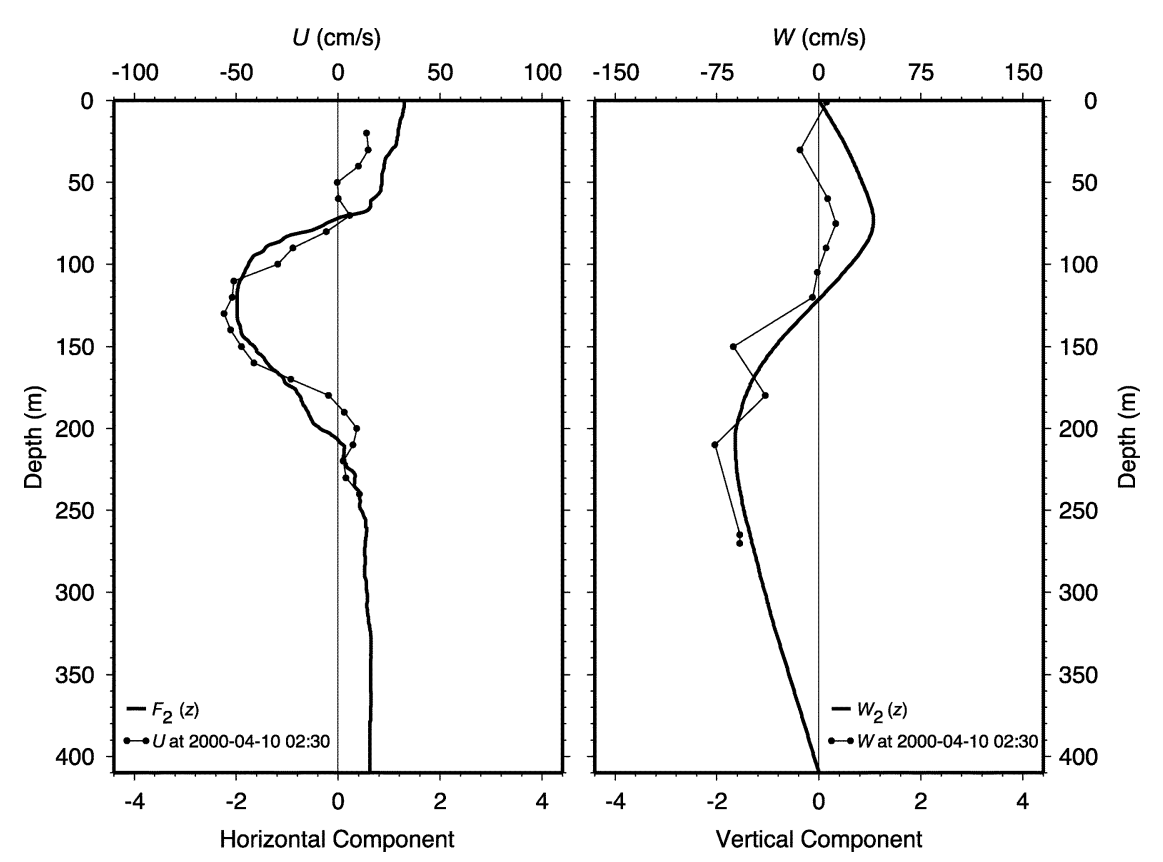

Fig. 11. Left panel: vertical profiles of $F_{2}(z)$ (bold line) and observed $U$ (thin line) for the second baroclinic mode soliton that occurred on 0230 GMT April 10, 1999. The observed $U$ has been high-pass filtered to exclude fluctuations with duration longer than $5 \mathrm{~h}$. Right panel: $W_{2}(z)$ (bold line) and the estimated vertical velocity ( $W$, thin line) of the second baroclinic mode soliton at 12 depths. The amplitude of $F_{2}(z)$ is arbitrary.

where $W_{z=150}$ and $W_{z=265}$ are the amplitude of $W_{1}$ at 150 and $265 \mathrm{~m}$, respectively. For the six leading soliton amplitudes examined, the result for $\eta_{0,1, z=150}$ was $90 \pm 15 \mathrm{~m}$ and the largest leading soliton amplitude was around $106 \mathrm{~m}$, close to the estimate of Liu et al. [13]. Using the leading soliton amplitude in (11), results in a corresponding characteristic length $\left(\Delta_{1}\right)$ for that soliton of $1.35 \pm 0.66 \mathrm{~km}$. The ratio of the leading soliton amplitude to local depth was $0.21 \pm 0.04$, indicating that the internal soliton was a strong nonlinear wave [33]. The strong nonlinear effect could skew the waveform and the result coincides with that observation.

No estimate is made for the isopycnal displacement in 2000 because no proper data is available to compute the gradient of the background temperature. However, based on the large temperature fluctuation found in the third type of soliton in 2000 (Fig. 8, bottom), that feature likely had greater isopycnal displacement than the previous estimate.

\section{Phase Speed and Time Duration of Soliton}

Plugging $\eta_{0,1, z=150}, c_{1}$ (first baroclinic mode linear phase speed), and $\alpha_{1}$ [obtained from (8)] into (12), the nonlinear first baroclinic mode phase speeds $\left(C_{1}\right)$ of the six leading solitons observed in 1999 are estimated. Here, $C_{1}$ varies from 147 to $157 \mathrm{~cm} / \mathrm{s}$ with an average speed of $152 \pm 4 \mathrm{~cm} / \mathrm{s}$. The nonlinear phase speeds are clearly larger than the linear phase speed of $127 \mathrm{~cm} / \mathrm{s}$ estimated from the CTD profiles computed from (4).

The phase speed can also be estimated directly from the measurements and satellite images. Fig. 12 shows the SAR image from the Second European Remote Sensing Satellite (ERS-2) on 1443 GMT April 26, 2000, in the northern SCS. The image size is $400 \mathrm{~km} \times 100 \mathrm{~km}$. The image shows a near $200 \mathrm{~km}$ "bright-

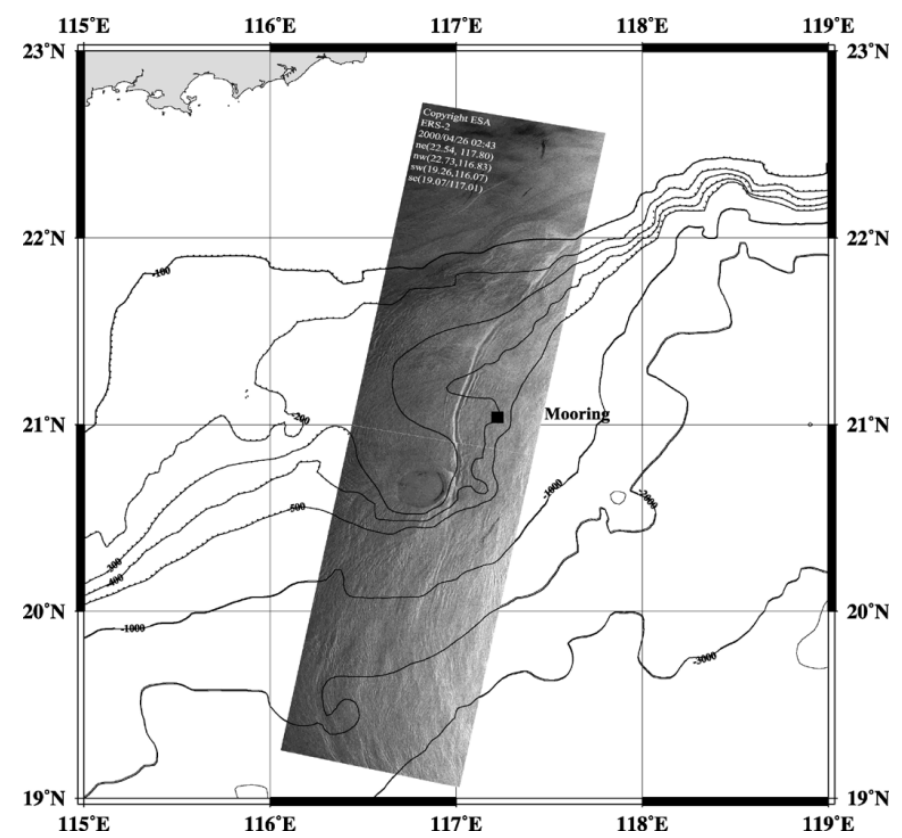

Fig. 12. ERS-2 SAR image obtained on 0423 GMT April 26, 2000, in the northern SCS showing the internal soliton pattern near Tung-Sha Island. The image size is $400 \mathrm{~km} \times 100 \mathrm{~km}$. The square represents the mooring location.

dark" wave crest near Tung-Sha Island, indicating a first baroclinic mode depression soliton [13]. The mooring measurement showed that a soliton emerged $3.7 \mathrm{~h}$ prior to the time the SAR image was acquired. The shortest distance between the wave crest (shown on images) and the mooring location was about $22 \mathrm{~km}$. Dividing this distance by the time difference, the estimated internal soliton propagation speed was around $165 \mathrm{~cm} / \mathrm{s}$, which is close to the nonlinear phase speed estimated before. 

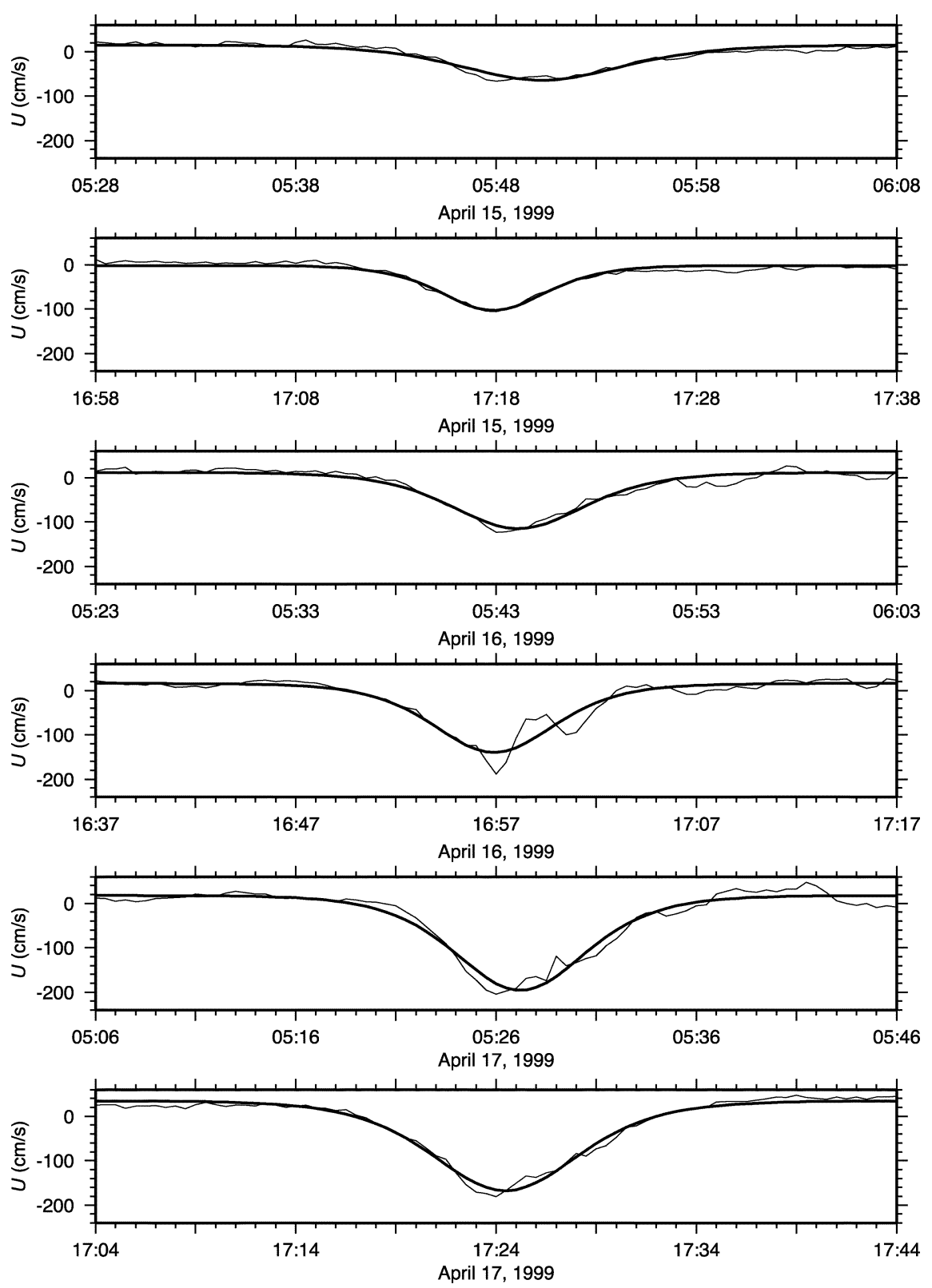

Fig. 13. Observed (thin line) and least-squares fit (bold line) of the $U$ velocity component and hyperbolic secant squared shape for the six solitons observed during April 1999. The observations were low-pass filtered to exclude fluctuations with duration longer than $5 \mathrm{~h}$.

Using (13), the 5-h high-pass filtered $U$ at $50 \mathrm{~m}$ could be fitted by a square of the hyperbolic secant function. Fig. 13 shows the 5-h high-pass filtered $U$ at $50 \mathrm{~m}$ and the corresponding fitted curve of the square of the hyperbolic secant for the six leading solitons that occurred in 1999. The two curves generally agree well. Clearly, the $\mathrm{KdV}$ solution of $U$ is still suitable to use in describing the $U$ fluctuation at $50 \mathrm{~m}$, even for the second type of soliton. The higher order nonlinear effects on $U$ could be small at that depth. Because of this good agreement, the square of a hyperbolic secant curve fitting was applied to all of the 40 first baroclinic mode leading solitons (except the one with the data gap) of $U$ to estimate the time scales of these solitons. The time scale $\tau$ is defined as $u_{1}(\tau / 2) / u_{0,1}<e^{-\pi}$. In general, the larger solitons had shorter time scales. The time scale varied from 16 to $25 \mathrm{~min}$ with an average of $19 \pm 4 \mathrm{~min}$. The value is quite similar with the time scale (20 min) that was chosen for the estimate of the isopycnal displacement.

\section{DISCUSSION AND SUMMARY}

For the second and third types of soliton, the phenomena of the asymmetry of the soliton form and the complexity of the time evolution of $U$ at mid-depths indicate that the soliton could reach the wave-breaking stage [22]. Two methods were applied to examine the wave-breaking stage; one is by examination of the ratio of the leading soliton amplitude $\left(\eta_{0,1}\right)$ to $h_{2}$. Here, $h_{2}$ is defined as the water thickness below the nodal point. When $h_{2}$ is only around a factor 2 or 3 times $\eta_{0,1}$, the soliton is going to break [34], [35]. The second type of soliton, presented in Section III, had values for $\eta_{0,1}$ and $h_{2}$ of $90 \pm 15$ 


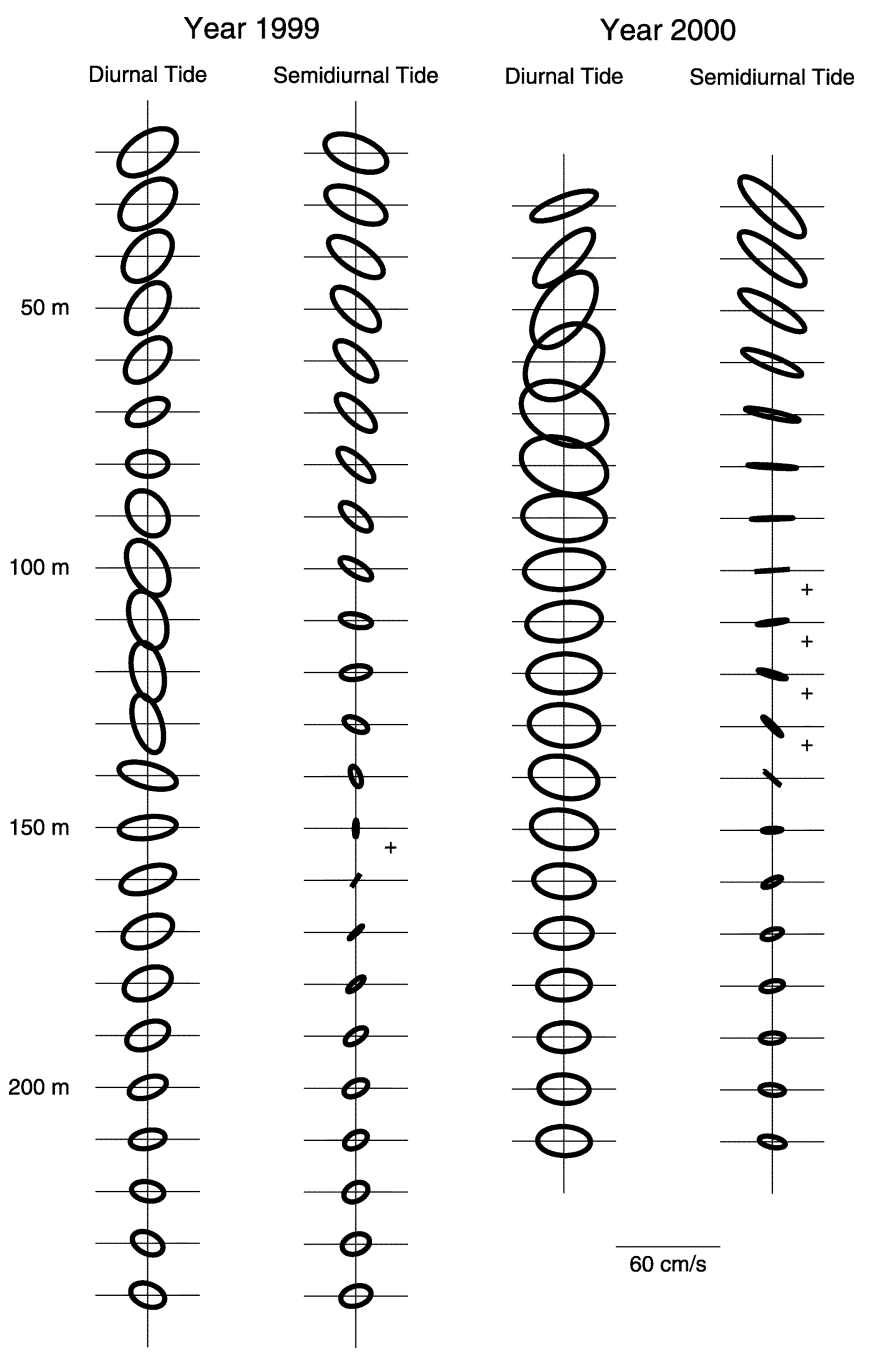

Fig. 14. Vertical distribution of horizontal tidal currents during (left) April 1999 and (right) April 2000. Both diurnal and semidiurnal ellipses are shown (in the $x-y$ plane). With the exception of the ones noted by a plus sign, all of the ellipses rotated clockwise.

and $276 \mathrm{~m}$, respectively. The value of $h_{2} / \eta_{0,1}$ is $3.18 \pm 0.70$. This result suggests that the soliton is close to or even on the breaking stage. Furthermore, the value of $h_{2} / \eta_{0,1}$ also suggests near overturning [22].

Another method for checking the soliton-breaking stage is to compare the maximum particle velocity $\left(u_{\max }\right)$ and phase speed (c). When $u_{\max }>c$ in a two-layer fluid [36] or $u_{\max }>0.8 c$ in a continuous stratification fluid [37], the soliton would break. Most of the second types of leading soliton had $u_{\max }$ near or even larger than the estimated nonlinear phase speed and the soliton is near or even on the breaking stage. It is a reasonable hypothesis that the third type of soliton could have larger $u_{\max }$ than the second type of soliton, because the former induced a much larger temperature fluctuation. The observed third type of soliton could then be in the process of breaking.

The diurnal and semidiurnal tidal ellipses in 1999 and 2000 are shown as a function of depth in Fig. 14. During both years, the diurnal tide appeared to be more barotropic than the semidiurnal tide. The semidiurnal tide had a nodal point near $150 \mathrm{~m}$ during 1999 and was more rectilinear near mid-depth during 2000. To further evaluate the barotropic
TABLE II

PERCENTAGE OF VARIANCE FOR EACH OF THE Four DYNAMICAL MODES AS DETERMINED BY A LiNEAR LEAST-SQUARES FIT RELATIVE TO THEIR SUM

\begin{tabular}{lcc}
\hline Dynamic Mode & Year 1999 & Year 2000 \\
\hline Diurnal Tide & & \\
Barotropic & $37.79 \%$ & $46.10 \%$ \\
First baroclinic & $22.22 \%$ & $30.62 \%$ \\
Second baroclinic & $16.04 \%$ & $10.34 \%$ \\
Third baroclinic & $23.95 \%$ & $12.93 \%$ \\
Semidiurnal & & \\
Barotropic & $13.85 \%$ & $7.05 \%$ \\
First baroclinic & $69.83 \%$ & $86.92 \%$ \\
Second baroclinic & $6.93 \%$ & $2.38 \%$ \\
Third baroclinic & $3.39 \%$ & $3.65 \%$ \\
\hline \hline
\end{tabular}

and baroclinic tidal current energies, band-pass filters were applied to obtain semidiurnal and diurnal current velocity time series at each depth. The frequency bandwidth was $0.008 \mathrm{c} / \mathrm{h}$ and was centered upon the $K_{1}$ and $M_{2}$ tidal frequencies for the diurnal and semidiurnal tides, respectively. These current velocity time series were then projected onto the barotropic and three baroclinic modes $\left(F_{n}(z)\right.$, where $n=0,1,2$, and 3$)$ by minimizing the mean-squared error between the band-passed current velocity and a linear combination of the modes. Finally, the variances of four modes were computed from the resulting projection time series [38]. The diurnal tidal variance was distributed over several modes with the largest percent of variance in the barotropic mode (Table II). The semidiurnal tidal variance was concentrated in the first baroclinic mode, which contained $69.8 \%$ and $86.9 \%$ of the variance during 1999 and 2000, respectively (Table II). More first baroclinic mode energy was, therefore, available to be transferred to the soliton from the semidiurnal tide than from the diurnal tide. This result could explain the observed semidiurnal occurrence of the solitons.

The second baroclinic mode soliton is rarely found in the nature, because it is an unstable disturbance. Konyaev et al. [39] had observed the second baroclinic mode soliton on the lee side of Mascarene Ridge in the Indian Ocean. They inferred that the barotropic tide over shallow abrupt topography (Mascarene Ridge) could generate the second baroclinic mode soliton via a hydraulic jump on the lee side. In laboratory and numerical model experiments, Vlasenko and Hutter [40] found that the first baroclinic mode soliton flowing over a sill could generate the second baroclinic mode soliton. In our field experiment, the only notable sills upstream of the mooring station were several hundred kilometers away in the Luzon Strait. An unstable mode-two wave is not likely to survive propagation across that distance. Also, the feature of the first baroclinic mode soliton appearing prior to the second baroclinic mode soliton was not observed. Therefore, neither of the previous two generation mechanisms provides a likely explanation for the observed second-mode soliton in the SCS.

Examining the historical CTD measurements around the mooring site, a three-layer fluid was sometimes seen in the spring. An example of such a distribution is shown in Fig. 15. Yih [41] has shown that a three-layer fluid system can have internal waves of first and second order. This result suggests that the generation of a second baroclinic mode soliton could arise from the barotropic or first baroclinic tidal flow encountering 


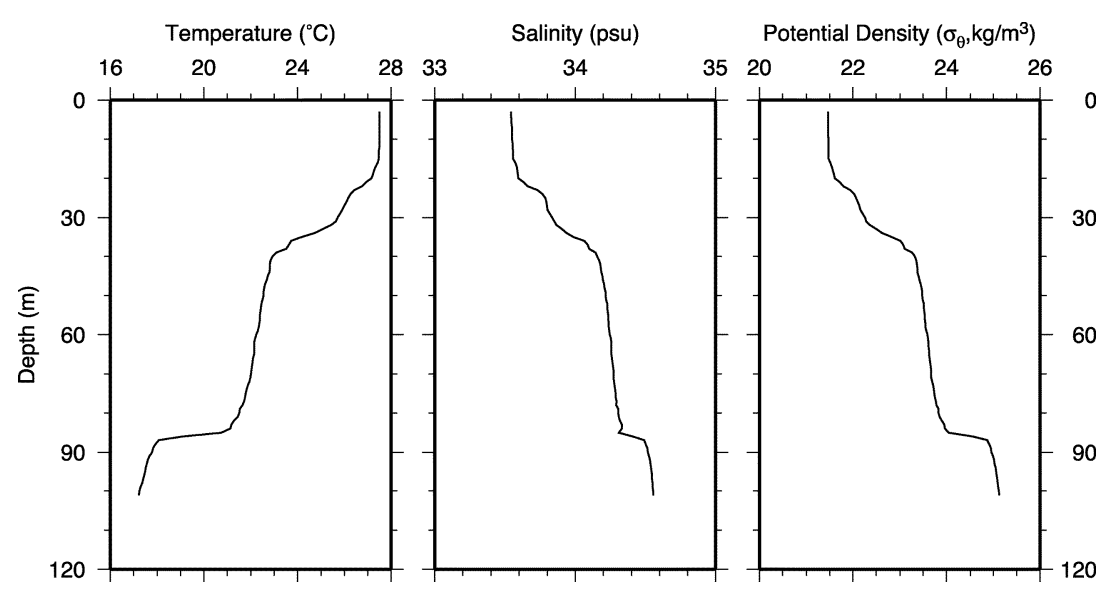

Fig. 15. Vertical profiles of (left panel) temperature, (middle panel) salinity, and (right panel) density on 2256 GMT May 20, 2001. The CTD data was obtained at $\left(21^{\circ} 55.8^{\prime} \mathrm{N}, 117^{\circ} 9.6^{\prime} \mathrm{E}\right)$, where the local water depth was $108 \mathrm{~m}$.

a three-layer fluid system and redistributing its energy into the second baroclinic mode soliton on the continental slope.

In the ASIAEX pilot studies, a mooring instrumented with an ADCP, VACMs, and a thermistor chain was deployed northeast of Tung-Sha Island, on the continental slope of the northern SCS, in April of 1999 and 2000. Upper-ocean current velocity and temperature at several depths were observed. The first baroclinic mode depression solitons were the dominant signal in the high-frequency band. The largest observed horizontal current speed, vertical displacement, and temperature fluctuation caused by the internal solitons were $240 \mathrm{~cm} / \mathrm{s}, 106 \mathrm{~m}$, and $11^{\circ} \mathrm{C}$, respectively. The internal solitons generally, coincided with the spring tide, also were irregularly seen during the neap tide period. The time interval between two leading solitons was around $12 \mathrm{~h}$. The nonlinear phase speed was around $152 \pm 4 \mathrm{~cm} / \mathrm{s}$, which is close to the estimated speed $(165 \mathrm{~cm} / \mathrm{s})$ from a single SAR image and the mooring measurements. The estimated speed was slightly larger than the theoretical linear phase speed, but in reasonable agreement given the error in the calculation.

The observed internal solitons were categorized into four types. The type- 1 soliton generally agreed with the KdV equation. It was away from the transition zone, where the depression wave gradually turns into an elevation wave, and was not too large. The type- 1 soliton occurred generally around the neap tide period and primarily propagated to the west. The time evolutions of current speed and temperature were symmetric. The current direction was westward in the upper layer and eastward in the lower layer and there was no time lag in the maximum current speeds between the upper and lower layers. The second and third types of solitons were in the transition zone before and close to the turning point, respectively. They generally occurred during the spring tide period and had amplitudes much larger than the type-1 soliton. The evolution of these solitons was asymmetric with the front steeper than the back. A temperature kink following the main soliton pulse was observed. The time evolution of $U$ at middle depths was complicated and could be related to higher order nonlinear and shoaling effects. Most of these type- 2 and type-3 solitons were close to or even at the breaking stage. The temperature fluctuations caused by the type-3 soliton were larger and the locus of the nodal point deeper than with the type- 2 solitons. The depth of the nodal point also varied with time, which was inconsistent with the KdV theory. Only one type- 3 soliton was observed and it was poorly sampled, but it appeared to be too large for small-amplitude theory to apply. The type-3 soliton was likely breaking, or near breaking, at the time it was observed.

The first three types of solitons were all first baroclinic mode depression waves. One rare mode two soliton was also observed and was called a type- 4 soliton. The type- 4 soliton likely arose due to a three-layer stratification of the water column, which occasionally happens in the region during spring.

\section{ACKNOWLEDGMENT}

The authors would like to thank the Center for Space and Remote Sensing Research, National Central University, Chung-Li, Taiwan, for processing the SAR image. They would also like to thank the captain and crew of the $R / V$ Ocean Researcher I and Dr. W. D. Liang and Mr. W. H. Her for preparing the moorings.

\section{REFERENCES}

[1] H. Sandstrom and J. A. Elliott, "Internal tide and solitons on the Scotian shelf: a nutrient pump at work," J. Geophys. Res., vol. 89, no. 4, pp. 6415-6426, 1984.

[2] J. B. Bole, C. C. Ebbesmeyer, and R. D. Romea, "Soliton currents in the South China Sea: measurements and theoretical modeling," in Proc. 26th Annual Offshore Technology Conf., Houston, TX, 1994, pp. 367-376.

[3] J. R. Apel, M. Badiey, C.-S. Chiu, S. Finette, R. Headrick, J. Kemp, J. F. Lynch, A. Newhall, M. H. Orr, B. H. Pasewark, D. Tielbuerger, A. Turgut, K. von der Heydt, and S. Wolf, "An overview of the 1995 SWARM shallow-water internal wave acoustic scattering experiment," IEEE J. Oceanic Eng., vol. 22, no. July, pp. 465-500, 1997.

[4] E. J. Katz, "Effect of the propagation of internal waves in underwater sound transmission," J. Acoust. Soc. Amer., vol. 42, no. 1, pp. 83-87, 1967. 
[5] J. F. Lynch, G. Jin, R. Pawlowicz, D. Ray, A. J. Plueddemann, C.-S. Chiu, J. H. Miller, R. H. Bourke, A. P. Parsons, and R. Muench, "Acoustic travel time perturbations due to shallow-water internal waves and internal tides in the Barents sea polar font: Theory and experiment," $J$. Acoust. Soc. Amer., vol. 99, no. 2, pp. 803-821, 1996.

[6] D. Rubenstein, "Observations of cnoidal internal waves and their effect on acoustic propagation in shallow water," IEEE J. Oceanic Eng., vol. 24, pp. 346-357, July 1999.

[7] “The 1998 WHOI/IOS/ONR Internal Solitary Wave Workshop," Woods Hole Oceanograph. Inst., Tech. Rep. WHOI-99-07, Woods Hole, MA, 1999.

[8] J. S. Russell, "Report on the committee on waves," in Proc. 7th Rep. Meet. Brit. Assoc. Adv. Sci., 1837, Liverpool, U.K., 1938, pp. 417-496.

[9] —_ "Report on waves," in 14th Rep. Meet. Brit. Assoc. Adv. Sci. , York, U.K., 1845, pp. 311-390.

[10] J. M. Boussinesq, "Théorie de l'intumescence liquide, appelée onde solitaire ou de translation, se propageant dans un canal rectangulaire," Acad. Sci. Paris, Comptes Rendus, vol. 72, pp. 755-759, 1871.

[11] D. J. Korteweg and G. deVries, "On the change of form of long waves advancing in a rectangular canal and on a new type of long stationary waves," Phil. Mag., vol. 39, pp. 422-443, 1895.

[12] N. J. Zabusky and M. D. Kruskal, "Interaction of "solitons" in a collisionless plasma and the recurrence of initial states," Phys. Rev. Lett., vol. 15, no. 6, pp. 240-243, 1965.

[13] A. K. Liu, Y. S. Chang, M.-K. Hsu, and N. K. Liang, "Evolution of nonlinear internal waves in the East and South China Seas," J. Geophys. Res., vol. 103, no. 4, pp. 7995-8008, 1998.

[14] R. Grimshaw, E. Pelinovsky, and T. Talipova, "Solitary wave transformation in a medium with sign-variable quadratic nonlinearity and cubic nonlinearity," Physica D, vol. 132, no. 1/2, pp. 40-62, 1999.

[15] J. Small, "A nonlinear model of shoaling and refraction on interfacial solitary waves in the ocean. part I: development of the model and investigations of the shoaling effect," J. Phys. Oceanogr., vol. 31, no. 11, pp. 3163-3183, 2001.

[16] C.-Y. Lee and R. C. Beardsley, "The generation of long nonlinear internal waves in a weakly stratified shear flow," J. Geophys. Res., vol. 79, no. 1, pp. 453-462, 1974.

[17] N. J. Balmforth, "Solitary waves and homoclinic orbits," Annu. Rev. Fluid Mech., vol. 27, pp. 335-373, 1995.

[18] R. Grimshaw, E. Pelinovsky, and T. Talipova, "The modified KrotewegdeVries equation in the theory of large-amplitude internal soliton," Nonlinear Proc. Geophys., vol. 4, no. 4, pp. 237-250, 1997.

[19] R. S. Johnson, "Solitary wave, soliton and shelf evolution over variable depth,” J. Fluid Mech., vol. 276, pp. 125-138, 1994.

[20] P. J. Lynett and P. L.-F. Liu, "A two-dimensional, depth-integrated model for internal wave propagation over variable bathymetry," Wave Motion, vol. 36, no. 3, pp. 221-240, 2002.

[21] R. Grimshaw, E. Pelinovsky, and T. Talipova, "Solitary wave transformation due to a change in polarity," Stud. Appl. Math., vol. 101, no. 4, pp. 357-388, 1998.

[22] V. Vlasenko and K. Hutter, "Numerical experiments on the breaking of solitary waves over a slope-shelf topography," J. Phys. Oceanogr., vol. 32, no. 6, pp. 1779-1793, 2002.

[23] R. Fett and K. Rabe, "Satellite observation of internal wave refraction in the South China Sea," Geophys. Res. Lett., vol. 4, no. 5, pp. 189-191, 1977.

[24] C. C. Ebbesmeyer, C. A. Coomes, R. C. Hamilton, K. A. Kurrus, T. C. Sullivan, B. L. Salem, R. D. Romea, and R. J. Bauer, "New observations on internal waves (solitons) in the South China Sea using an acoustic Doppler current profiler," in Marine Technology Society 91 Proceedings, New Orleans, 1991, pp. 165-175.

[25] M.-K. Hsu, A. K. Liu, and C. Liu, "A study internal waves in the China Seas and Yellow Sea using SAR," Cont. Shelf Res., vol. 20, no. 4/5, pp. $389-410,2000$

[26] A. R. Osborne and T. L. Burch, "Internal solitons in the Andaman Sea," Sci., vol. 208, no. 4443, pp. 451-460, 1980.

[27] J. R. Apel, J. R. Holbrook, A. K. Liu, and J. J. Tsai, "The Sulu Sea internal soliton experiment," J. Phys. Oceanogr., vol. 15, no. 12, pp. 1625-1651, 1985.

[28] J. W. Loder, D. Brickman, and E. P. W. Horne, "Detailed structure of currents and hydrography on the northern side of Georges Bank," J. Geophys. Res., vol. 97, no. 9, pp. 14331-14351, 1992.
[29] R. Pinkel, "Internal solitary waves in the warm pool of the western equatorial Pacific," J. Phys. Oceanogr., vol. 30, no. 11, pp. 2906-2926, 2000.

[30] M. Remoissenet, Waves Called Solitons. Berlin, Germany: Spring-Verlag, 1999, ch. 3.

[31] V. Vlasenko, P. Brandt, and A. Rubino, "Structure of large-amplitude internal solitary waves," J. Phys. Oceanogr., vol. 30, no. 9, pp. 2172-2185, 2000.

[32] A. E. Gill, Atmosphere-Ocean Dynamics. San Diego, CA: Academic, 1982, ch. 6.

[33] J. W. Miles, "On internal solitary waves," Tellus, vol. 31, no. 5, pp. 456-462, 1979.

[34] K. R. Helfrich and W. K. Melville, "On long nonlinear waves over slopeshelf topography," J. Fluid. Mech., vol. 167, pp. 285-308, 1986.

[35] K. R. Helfrich, "Internal solitary waves breaking and run-up on a uniform slope," J. Fluid Mech., vol. 243, pp. 133-154, 1992.

[36] K. Saffarinia and T. W. Kao, "A numerical study of the breaking of internal soliton and its interaction with a slope," Dyna. Atmos. Oceans, vol. 23, no. 1/4, pp. 379-391, 1996.

[37] J. Grue, A. Jensen, P.-O. Rusås, and J. K. Sveen, "Breaking and broadening of internal solitary waves," J. Fluid. Mech., vol. 413, pp. 181-217, 2000.

[38] T. Y. Tang, R. H. Weisberg, and D. Halpern, "Vertical structure of low frequency variability in the eastern equatorial Pacific Ocean," J. Phys. Oceanogr., vol. 18, no. 7, pp. 1010-1019, 1988.

[39] K. V. Konyaev, K. D. Sabinin, and A. N. Serebryany, "Large-amplitude internal waves at the Mascarene Ridge in the Indian Ocean," Deep-Sea Res. I, vol. 42, no. 11/12, pp. 2075-2091, 1995.

[40] V. I. Vlasenko and K. Hutter, "Generation of second mode solitary waves by the interaction of a first mode soliton with a sill," Nonlinear Proc. Geophys., vol. 8, no. 4/5, pp. 223-239, 2001.

[41] C.-S. Yih, "Gravity waves in a stratified fluid," J. Fluid Mech., vol. 8, pp. $481-508,1960$.

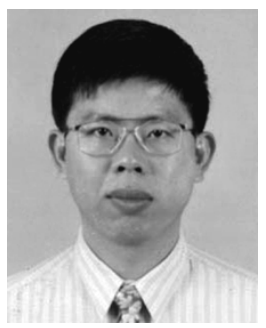

Ying-Jang Yang was born in Taiwan, R.O.C., in 1967. He received the B.S. degree in oceanography from the National Taiwan Ocean University, Keelung, Taiwan, in 1990, and the Ph.D. degree in physical oceanography from the National Taiwan University, Taipei, Taiwan, in 1996.

$\mathrm{He}$ currently is an Assistant Professor with the Department of Marine Science, Chinese Naval Academy, Kaohsiung, Taiwan. His research interests include internal tides and waves, current variation around Taiwan, and equatorial dynamics.

Dr. Yang is a Member of the American Geophysical Union.

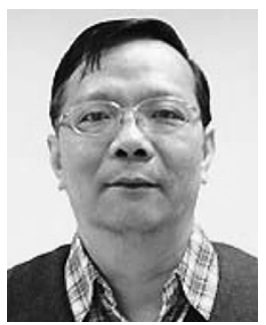

Tswen Yung Tang was born in Taiwan, R.O.C., in 1952. He received the M.S. degree in physical oceanography from National Taiwan University, Taipei, in 1975, and the Ph.D. degree in physical oceanography from North Carolina State University, Raleigh, in 1984.

In August 1993, he was appointed Professor of Physical Oceanography at the Institute of Oceanography, National Taiwan University. He was appointed Program Manager of the Division of Marine Science, National Science Council, Taiwan, in January 2004. His research interests include equatorial dynamics, variability of upstream of Kuroshio, Kuroshio intrusion at Luzon Strait, circulation in the South China Sea, and internal waves. 


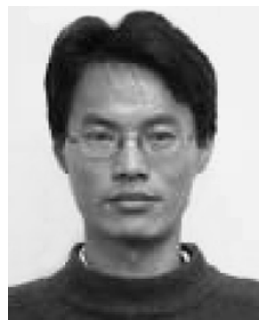

M. H. Chang was born in Taiwan, R.O.C., in 1975. He received the B.S. degree in oceanography from National Taiwan Ocean University in 2001 and the M.S. degree in physical oceanography from National Taiwan University, Taipei, in 2003.

$\mathrm{He}$ is currently a Research Assistant in the Ocean Data Bank, National Center for Ocean Research, Taiwan. He works on hydrographic data management and technical development. His current interests include the development and quality control of hydrographic data and calibration methods for the shipboard Acoustic Doppler Current Profiler (ADCP).

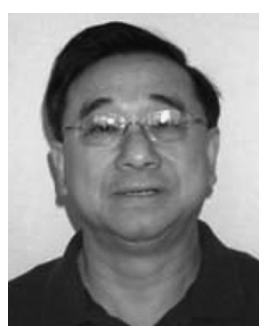

Antony K. Liu received the B.Sc. degree from National Chung-Hsing University, Taichung, Taiwan, R.O.C., in 1970, specializing in applied mathematics, and the Ph.D. degree in mechanics from the Johns Hopkins University, Baltimore, MD, in 1976.

Before he joined the NASA Goddard Space Flight Center, Greenbelt, MD, in 1986, he was with Dynamics Technology, Inc., Torrance, CA, as a Research Scientist, Group Manager, and later Section Head of Ocean Technology. He was promoted to Senior Scientist in 1992 at the Oceans and Ice Branch, Laboratory for Hydrospheric Processes, NASA/GSFC. Currently, he is in a three-year assignment detailed from NASA to the Office of Naval Research (ONR) Global-Asia, Tokyo, Japan. He has been a Principal Investigator (PI) of many research programs for the European Space Agency, the Japan Space Agency (JAXA), the Canadian Space Agency, and NASA. He also is a PI on ONR's Surface Wave Dynamics Experiment (SWADE) and Asian Seas International Acoustics Experiment (ASIAEX) and the National Oceanic and Atmospheric Administration's (NOAA's) CoastWatch projects. His research interests involve air-sea-ice interaction, satellite image processing, coastal monitoring, and nonlinear internal wave study.

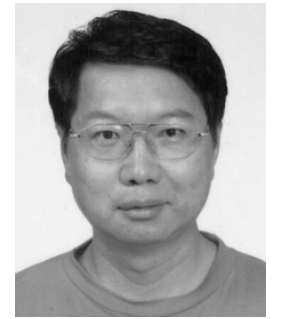

Ming-Kuang Hsu received the B.S. and M.S. degrees in hydraulic and ocean engineering from the National Cheng-Kuang University, Taichung, Taiwan, R.O.C., in 1973 and 1975, respectively, and the Ph.D. degree in ocean engineering from the Oregon State University, Corvallis, in 1986.

He was as an Associate Professor and Professor in the Department of Oceanography, National Taiwan Ocean University, Keelung, (1991-2004), where he worked on using SAR images and field experiments to study the mesoscale and small-scale ocean features near Taiwan. He currently is a Professor with Kung Wu Institute of Technology, Taipei, Taiwan, R.O.C., and is involved in the study of the generation and evolution of nonlinear internal waves in the South China Sea using in situ measurements and satellite data

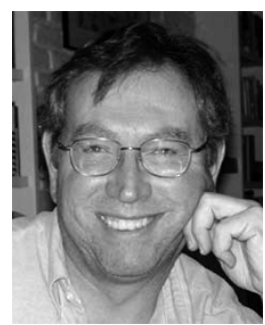

Steven R. Ramp received the M.S. degree in physical oceanography from the University of Washington, Seattle, in 1976, and the Ph.D. degree in physical oceanography from the University of Rhode Island, Narragansett, in 1986.

Since 1986, he has been with the U.S. Navy as a Professor at the Naval Postgraduate School, Monterey, CA, and a Program Officer at the Office of Naval Research, Arlington, VA. Prior to this, he spent time at the National Marine Fisheries Service, Woods Hole, MA. His research specialty is ocean observations from both ships and oceanographic moorings, and he has organized major expeditions to the Japan Sea, East China Sea, and South China Sea. He was the International Scientific Coordinator for the Asian Seas International Acoustics Experiment (ASIAEX). 